Bharti Vidhi (Orcid ID: 0000-0002-7710-169X)

Fairall Christopher, W. (Orcid ID: 0000-0003-4073-7413)

Blomquist Byron, W. (Orcid ID: 0000-0002-3366-6269)

HUANG Yi (Orcid ID: 0000-0001-8144-1227)

Protat Alain (Orcid ID: 0000-0002-8933-874X)

\title{
Air-sea heat and momentum fluxes in the Southern Ocean
}

Vidhi Bharti ${ }^{1,2}$, Christopher W. Fairall ${ }^{3}$, Byron W. Blomquist ${ }^{3}$, Yi Huang ${ }^{4,5}$, Alain Protat $^{6}$, Peter P. Sullivan ${ }^{3}$, Steven T. Siems ${ }^{1,2}$, Michael J. Manton ${ }^{1}$

${ }^{1}$ School of Earth, Atmosphere and Environment, Monash University, Victoria, Australia ${ }^{2}$ Australian Research Council Centre of Excellence for Climate System Science, Monash University, Victoria, Australia

${ }^{3}$ National Oceanic and Atmospheric Association, Earth Systems Research Laboratory, Physical Sciences Division, Boulder, CO, USA

${ }^{4}$ School of Earth Sciences, The University of Melbourne, Victoria, Australia

${ }^{5}$ Australian Research Council Centre of Excellence for Climate Extremes, The University of Melbourne, Victoria, Australia

${ }^{6}$ Australian Bureau of Meteorology, Melbourne, Victoria, Australia

Corresponding author: Vidhi Bharti (vidhi.bharti@monash.edu)

This article has been accepted for publication and undergone full peer review but has not been through the copyediting, typesetting, pagination and proofreading process which may lead to differences between this version and the Version of Record. Please cite this article as doi: 10.1002/(ISSN)2169-8996 


\section{Abstract}

The Clouds, Aerosols, Precipitation, Radiation, and atmospherlc Composition Over the southeRn oceaN (CAPRICORN) experiment was carried out in March-April 2016 onboard R/V Investigator studying momentum $(\tau)$, sensible heat $\left(H_{s}\right)$ and latent heat $\left(H_{l}\right)$ fluxes over the Australian sector of the Southern Ocean including over one cyclonic cold-core and one anticyclonic warm-core mesoscale oceanic eddy. The turbulencebased flux measurements obtained with the NOAA PSD flux system employing eddy covariance (EC) and inertial dissipation (ID) methods are compared with those obtained by the Coupled Ocean-Atmosphere Response Experiment (COARE) 3.5 bulk model, and the neutral transfer coefficients are studied. The relative uncertainty between the turbulence-based and COARE 3.5 estimates of $\tau, H_{s}$ and $H_{l}$ are $22 \%, 70 \%$ and $26 \%$, respectively at 1 -hour timescale over the Southern Ocean. Further, the variability in bulk fluxes is investigated with respect to oceanic eddies, precipitation events, atmospheric stability and extratropical cyclones encountered during the voyage. The main observed variability is an increase in significant wave height or $\gamma_{w}$ ( 33\%), $\tau(\sim 89 \%), H_{s}(\sim 187 \%)$ and $H_{l}(\sim 79 \%)$ over the warm eddy as compared to average voyage values. During the passage of 6 extratropical cyclones, an increase in $\tau\left(\sim 62 \%\right.$ average) and a decrease in $H_{s}(\sim 235 \%)$ and $H_{l}(\sim 79 \%)$ is noted in the warm sector, compared to pre-storm conditions, but the pattern reverses behind the cold front.

\section{Introduction}

The quantification of the energy budget of the Southern Ocean (SO) remains a challenge in global climate models due to large uncertainties associated with air-sea fluxes [Dong et al., 2007; Trenberth and Fasullo, 2010; Cerovečki et al., 2011; Bourassa et al., 2013]. Several past studies have been conducted over the SO to understand the various aspects of momentum $(\tau)$, sensible $\left(H_{S}\right)$ and latent $\left(H_{l}\right)$ heat fluxes [Morrow et al., 1992; Slonaker and van Woert, 1999; O'Neill et al., 2003; Hande et al., 2012; Jiang et al., 2012; Messager et al., 2012; Schulz et al., 2012; Song and Yu, 2012; Herman, 2015; Hausmann et al., 2016]. Nevertheless, the environmental dependencies of airsea interaction remain uncertain owing to inadequate reliable sampling and limited research into key intrinsic processes.

The SO is well-known for extreme wind-wave conditions where precipitation, sea spray and cloud cover play crucial roles in determining the air-sea heat and momentum fluxes. The strong winds cause wave-breaking and produce massive amounts of sea spray influencing energy and mass exchange significantly at the interface [Andreas and Monahan, 2000; Richter and Sullivan, 2014]. The region is also characterized by intense oceanic eddy activity coupled with the SO storm track due to its unique geographic location. The prominence of mesoscale oceanic eddies in the Antarctic Circumpolar Current due to the polar front substantially contributes to the poleward heat transport and generates the vertical transport of momentum deep into 
the ocean [Hausmann and Czaja, 2012; Olbers et al., 2012]. However, their distinct contributions to the ocean heat budget are yet to be fully resolved despite recent evidence of their influence on marine atmospheric boundary layer turbulence, cloud properties and precipitation [Greatbatch et al., 2007; Frenger et al., 2013; Bôas et al., 2015]. Further, the SO meteorology is dominated by extratropical cyclones where turbulent fluxes can significantly vary within different sectors. Previous studies suggest that surface fluxes are related to the sea state and affect storm evolution including precipitation [Beare, 2007; Persson et al., 2008]. The diurnal variability of sea surface temperature [Kawai and Wada, 2007] and sensible cooling due to rainfall are basic aspects of air-sea interaction yet to be fully understood in the SO.

The global climate community set a goal to resolve individual components of the surface heat budget accurate to within $5 \mathrm{Wm}^{-2}$ at $1^{\circ}$ spatial resolution and 3-6 $\mathrm{h}$ temporal resolution [Curry et al., 2004]. However, different surface flux products report large variances and inconsistencies in the magnitude of fluxes over the SO [Liu et al., 2011; Yu et al., 2011]. The biases in satellite infrared retrievals of sea surface temperature, large uncertainties of cloud properties, mesoscale eddies and atmospheric fronts as well as inadequate representation of diurnal fluctuations of sea surface temperature could be potential sources of errors in satellite flux products. Reanalyses models are progressively improving yet their performance must be evaluated over this region.

Acquiring direct flux measurements from ships has several logistical challenges, particularly in high wind regions $\left(>15 \mathrm{~ms}^{-1}\right)$ but are crucial for the modulation of indirect flux parameterization schemes. The Coupled Ocean-Atmosphere Response Experiment (or COARE) bulk parameterization model for air-sea fluxes was developed initially for implementation in the tropics and mid-latitudes [Brunke et al., 2003; Fairall et al., 2003; Edson et al., 2013]. Since its publication in 1996 [Fairall et al., 1996], it has become a popular method to estimate turbulent fluxes over the air-sea interface. However, the model has not been extensively validated for Polar oceans featuring diverse conditions notably extreme and light wind conditions, rough sea state, extratropical cyclones, mesoscale eddies, and large near-surface ocean temperature gradients.

Considering these issues and the need for new observations, a field campaign was carried out onboard the $R / V$ Investigator, named CAPRICORN (Clouds, Aerosols, Precipitation, Radiation, and atmospherlc Composition Over the southeRn oceaN) 2016. The field program was conducted in March - April 2016 to collect high quality in situ observations of fluxes, clouds, aerosols, precipitation and ocean properties over the Australian sector of the SO [Mace and Protat, 2018]. One of the major objectives was to advance our knowledge of the boundary layer structure and the surface energy budget in this region. One cyclonic cold core eddy (or cold eddy) and one anticyclonic warm core eddy (or warm eddy) were sampled during the voyage. 
In the present paper, section 3.1 discusses the comparison between measured and parameterized momentum and heat flux estimates. An evaluation of neutral transfer coefficients with respect to wind speed and the association of momentum flux with wave age is discussed in section 3.2. Further, the paper addresses the basic aspects of flux variability using COARE 3.5 bulk fluxes over oceanic eddies (section 3.3), precipitation (section 3.4), atmospheric stability (section 3.5), and extratropical cyclonic storms (section 3.6) encountered during the voyage. Through the present study, we attempt to understand the physical mechanisms modulating the air-sea interactions over the SO.

\section{The CAPRICORN 2016 Experiment}

The $R / V$ Investigator departed from Hobart (Tasmania) on March 14, 2016, starting from $43^{\circ} \mathrm{S}$ reaching $53^{\circ} \mathrm{S}$, touching the Subantarctic Front and returned Hobart by April 15, 2016. No flux observations were available from 23 to 26 March due to ship maintenance.

This voyage was one of the first efforts to quantify the turbulent fluxes over the Australian sector of the SO including at high wind speeds. Figure 1a depicts the ship track during the voyage along with the marked (dashed ellipses) locations of the cold core and warm core eddies. Figure $1 \mathrm{~b}$ shows a spatial map of gridded sea level anomalies (GSLA) which was used to identify the nature and location of mesoscale oceanic eddies.

The measurements were taken during multiple transects over the cold eddy for 6 days from March 30, 2016, to April 5, 2016, starting from the western edge of the eddy at $146.01^{\circ} \mathrm{E}, 50.37^{\circ} \mathrm{S}$. The size of the cold eddy was approximately $140 \times 110 \mathrm{~km}$. The warm eddy was part of a forming meander (roughly $120 \mathrm{~km}$ wide) and was sampled for approximately 4 days starting from April 6 to April 10, 2016. However, only two transects were conducted due to time limitations.

\subsection{Instrumentation and measurement techniques}

The National Oceanic and Atmospheric Administration, Physical Sciences Division (NOAA PSD) air-sea flux system (table 1) consists of a fast-response turbulence sensor system for wind speed and water vapour with ship motion corrections, solar and infrared (IR) radiation sensors, bulk pressure, temperature, and humidity sensors, and an optical rain gauge. Most instruments were installed on the bow jackstaff of the ship at a height of $19.5-21 \mathrm{~m}$ above the water. A sea surface temperature sensor (sea snake) consisting of a floating thermistor (depth $\sim 5 \mathrm{~cm}$ ) was deployed off the port-side bow outrigger boom. The observations were obtained at a sampling rate of $1 \mathrm{~Hz}$ and $10 \mathrm{~Hz}$ for slow and fast sensors, respectively. The implementation of the system is discussed in Fairall et al. (1997). 
The standard eddy covariance (EC) and inertial dissipation (ID) methods are used for obtaining direct flux measurements [Large and Pond, 1981, 1982; Fairall et al., 1990]. The background on the similarity theory and the equations governing the turbulent fluxes are discussed in Fairall et al., (1996), Fairall et al., (2003) and Bradley \& Fairall (2006). The ID method is discussed in detail in Appendix B. The description of COARE 3.5 bulk parameterization model can be found in the Supporting Information S1.

\subsection{Surface and synoptic conditions}

The voyage summary discusses the surface conditions for each day of the voyage [Trull, 2016]. The average sunrise to sunset duration lasted from 0600 to 1900 local time, with the voyage enclosing the autumnal equinox. Six extratropical cyclones were encountered throughout the voyage. Rainfall was observed $\sim 30 \%$ of the voyage duration with the average hourly precipitation rate of $0.56 \mathrm{mmh}^{-1}$ and a maximum rain rate of $19.88 \mathrm{mmh}^{-1}$. Time series of atmospheric and oceanic measurements are shown in figure 2 . During the voyage, $10-\mathrm{m}$ neutral wind speed, $U_{10 n}$, ranged from 0.40 $-\sim 21 \mathrm{~ms}^{-1}$, with the average relative wind speed recorded as $10.93 \mathrm{~ms}^{-1}$.

The sea state can be described using various wave parameters. Earlier research indicated that the Charnock parameter and, in turn, the sea surface roughness should be affected by the fetch and wave steepness, which are functions of wave age and height respectively (Drennan et al. 2005 and references therein). In the present paper, significant wave height, $\gamma$ (4 times the RMS surface vertical displacement), wind-sea significant wave height, $\gamma_{w}$ and inverse wave age, $\left(u_{*} / C_{p}\right)$ are used to define the sea state. The significant wave height, $\gamma$, accounts for the open ocean wave-field that includes both locally and non-locally generated waves (i.e. combined wind-sea and swell heights), whereas $\gamma_{w}$ is the wave height for local wind-sea waves (i.e. excludes swell). $\gamma_{w}$ is estimated from the 1D Riegl wave spectra assuming that the wind-sea is in equilibrium with the mean wind. An approximate separation or cut-off frequency $\left(F_{w}\right)$ that partitions the wave spectrum into wind-sea and swell peaks is calculated as $F_{w}=0.8 \times g /\left(2 \pi \times U_{10 n}\right)$ where $g$ is the acceleration of gravity as described by Gilhousen and Hervey (2002). However, the Doppler correction has not been applied to the laser measurements that might produce a bias to the determination of the wind sea partition at higher wind and ship speeds, as well as our ability to accurately estimate the phase speed of the waves and thereby their wave-age. $\gamma_{w}$ is the integral of the wave spectrum from the cut-off frequency up to the high frequency limit of the data, excluding the low frequency swell peak. The wave age is defined as, $C_{p} / u_{*}$ with $C_{p}=g T_{p} / 2 \pi$ defined as the phase speed of the dominant wave, $T_{p}$ is spectral peak period and $u_{*}$ is friction velocity. The non-dimensional wave age captures the development of the sea state in response to wind stress over time and has a value of about 30 for a fully developed sea with values below and above it for a younger and decaying sea state, respectively. The inverse wave age $\left(u_{*} / C_{p}\right)$ is often used because this form compresses the range of old, swell dominated seas and expands the range 
of young sea state conditions. For a fully developed sea, $u_{*} / C_{p}$ is $\approx 0.03$ with larger values indicative of younger sea. $u_{*} / C_{p}$ ranges from 0.002 to 0.14 with a mean of 0.029 during the current voyage.

\subsection{Identifying weather fronts}

The traversal of cyclonic storms is associated with sudden changes in wind speed, wind direction, precipitation and sea state, subsequently impacting surface fluxes. The extratropical cyclones are defined with two criteria: First, hourly Himawari-8 satellite images of cloud top pressure (CTP) and cloud top temperature (CTP) are visually analysed and the band of clouds having CTP $<550 \mathrm{hPa}$ and $\mathrm{CTT}<-25^{\circ} \mathrm{C}$ moving from west to east passing above the ship are associated with the passage of extratropical cyclones. Second, based on the surface observations of pressure $(P)$, temperature $\left(T_{a}\right)$ and wind direction $(W)$, a cyclonic event is identified as when

$$
\frac{d^{2} P}{d t^{2}}>0.1 h P a h^{-2}, \frac{d T_{a}}{d t}<-0.2^{\circ} \mathrm{Ch}^{-1} \text { and } \frac{d W}{d t}<-5^{\circ} h^{-1}
$$

following Wang et al. (2015). Figure 2a identifies cold fronts on the time series of the surface pressure. As outlining the precise boundaries of the warm sector and the cold front is ambiguous, the leading edge of the cloud cover defines the start of the warm sector. Thus, the duration of the cloud band above the ship characterizes the period when the ship is within (or the midst-) of the cyclone. The relative minimum of pressure accompanied by precipitation near (mostly just before) the trailing edge of the cloud band defines the location of the cold front. The 12-hours prior to the start of the cloud cover is assumed as pre-cyclonic (or pre-) conditions. The 12-hour window after the end of the cloud band defines the post-frontal (or post-) conditions. Altogether, nine cyclones were identified during the voyage (table 2 ) with two during the cold eddy ( 31 March and 04 April) and one during the warm eddy (06 April) sampling. The cyclones identified on 23, 24 and 25 March were discarded due to instrument maintenance. We examined flux variability for strictly pre- and post-frontal conditions, noting, however, that pre- and post-frontal boundaries of a cyclone are highly variable and difficult to be delineated precisely.

\section{Results and discussion}

\subsection{Comparison of COARE 3.5 bulk fluxes with turbulent fluxes}

As a result of preliminary quality control, $\sim 48 \%$ of the measurements of latent heat flux using EC and ID methods were discarded due to wet conditions and sea salt contamination on the water vapour sensor optics (Licor LI7500). The empirical correction developed for the $R / V$ Ronald $H$. Brown cruise data [Fairall et al., 2003; Edson et al., 2011] is applied to the relative winds to account for flow distortion in the current dataset. The bow-mast location and height for the $R / V$ Investigator are similar to those of the $R / V$ Brown. This correction has been successful on other ships with similar setups (see also Fig. 3 in Dupuis, [2003]). 
The 10-minute fluxes and associated means were then processed to hourly averages based on an additional set of selection criteria as discussed in Fairall et al. (2003) and Zeng et al. (1998), as follows: i) relative wind direction with respect to the bow (minimum $-60^{\circ}$ to maximum $60^{\circ}$ with max std dev $15^{\circ}$ over 10 minutes), ii) rain rate (max $1 \mathrm{mmh}^{-1}$ ), iii) ship speed (max standard deviation $0.6 \mathrm{~ms}^{-1}$ and max speed $3.5 \mathrm{~ms}^{-}$ $\left.{ }^{1}\right)$, iv) ship heading ( $\max$ std dev $5^{\circ}$ ), v) port-starboard platform velocity from ship roll (max std dev $0.8 \mathrm{~ms}^{-1}$ ), and vi) flow distortion tilt angle at the top of the bow jack staff $\left(\max 10^{\circ}\right)$. Figure $3(\mathrm{a})$ shows the change in wind stress values with respect to relative wind direction from the bow and change in relative wind direction with respect to the mean airflow tilt angle justifying the criteria (i) and (vi).

The hourly mean turbulent fluxes (average of hourly EC and ID observations) were compared with the hourly COARE 3.5 bulk model outputs [Bariteau et al., 2018]. The COARE fluxes are computed with wind speed in the Earth reference frame, which ignores the contribution of surface currents. The ship provided two sources to estimate currents (the $25 \mathrm{~m}$ deep range on the acoustic Doppler current profiler (ADCP) and a surface drift estimates), but these were poorly correlated, and we decided not to use them. Surface current speeds were measured from the surface drift which gave magnitudes from $0-1 \mathrm{~ms}^{-1}$ with an average magnitude of about $0.5 \mathrm{~ms}^{-1}$. This value represents an error of $8 \%$ in $\tau$ and $4 \%$ in $H_{s}$ and $H_{l} . H_{s}$ and $H_{l}$ are positive when transporting energy away from the surface (i.e. into the atmosphere). The momentum flux is positive downward (i.e. from the atmosphere to the ocean). Radiation is positive when directed towards the ocean.

The turbulent and bulk model momentum fluxes correlate strongly $\left(R^{2}=0.90\right)$ at hourly time scales as shown in figure $3 \mathrm{~b}$. The flux comparisons are summarized in Table 3 , which confirms the good agreement in stress. The mean ID value of $H_{l}$ is higher than both EC and COARE 3.5 values and there is a clear high bias in the Figure $3 \mathrm{~d}$ scatterplot. The table also shows that the COARE estimates of $H_{l}$ are in better agreement with EC+ID than the ID estimates are with EC. It also shows there is a great deal of uncertainty between all three estimates of $H_{s}$. The mean value of $H_{s}$ computed by COARE 3.5 is slightly lower than the EC and ID mean, which is also evident in Figure 3c. The COARE 3.5 estimates of $H_{l}$ are in good agreement with the EC in the mean and overall as shown in Figure $3 \mathrm{~d}$.

The RMS difference between COARE and EC/ID displays a slight increase in $H_{l}$ during rain events (RMS difference of $30.5 \mathrm{Wm}^{-2}$ ) as compared with $H_{S}$ (RMS difference of $\left.15.5 \mathrm{Wm}^{-2}\right)$. COARE 3.5 fluxes are lower on average irrespective of wind speed $\left(U_{10 n}\right)$ and stability conditions (figures not included).

Overall, COARE 3.5 estimates of $\tau$ and $H_{l}$ are in good agreement with our EC values over the SO. COARE 3.5 gives slightly lower estimates of $H_{S}$ compared with the EC and ID values. However, the significance of the disagreement and EC/ID fluxes with COARE is difficult to evaluate because this is our first experience with this particular sonic anemometer and its characteristics are not well established. Appendix B presents an 
analysis of the temperature spectra from the Metek sonic anemometer that shows unexplained noise characteristics in weak to moderate temperature forcing. The disagreement between EC and ID fluxes is unusually large and weakens the validity of the comparison.

\subsection{Evaluation of neutral transfer coefficients}

The neutral transfer coefficient represents the same flux value had the measurements been made at $10 \mathrm{~m}$ height in neutral stratification (refer to S1). These are evaluated as functions of $U_{10 n}$ and $u_{*} / C_{p}$ in the present study. Figure 4 shows the comparison between measured and modelled transfer coefficients with error bars with respect to $U_{10 n}$. The average value of the coefficient is plotted per bin with a width of $1 \mathrm{~ms}^{-1}$. However, there are fewer than 5 data points for $<4 \mathrm{~ms}^{-1}$ and $>17 \mathrm{~ms}^{-1}$ wind speeds, hence, the measured transfer coefficients values are included only for wind speeds 4$17 \mathrm{~ms}^{-1}$ in the present analysis. We also cannot account for $<1 \mathrm{~ms}^{-1}$ conditions due to the lack of data. Since, there is high uncertainty in $H_{l}$ values of ID due to unknown reasons, we use $H_{l}$ values by EC method for the calculation of $C_{e 10 n}$.

The agreement is within $10 \%$ between measured and modelled $C_{d 10 n}$ for $4-17 \mathrm{~ms}^{-1}$ wind speeds. The mean modelled $C_{d 10 n}$ is $1.3( \pm 0.03) \times 10^{-3}$ and both mean modelled $C_{e 10 n}$ and $C_{h 10 n}$ are 1.1 ( \pm 0.04$) \times 10^{-3}$ for wind speeds $4-17 \mathrm{~ms}^{-1}$. The mean measured $C_{\text {h10n }}\left(1.4 \times 10^{-3}\right)$ is significantly higher than measured $C_{e 10 n}\left(1.1 \times 10^{-3}\right)$, which contradicts the results from COARE and Large and Pond (1982). The measured $C_{h 10 n}$ initially decreases with wind speed out to $7 \mathrm{~ms}^{-1}$ and then rises dramatically from a value of $1.1 \times 10^{-3}$ to $1.9 \times 10^{-3}$ at $16 \mathrm{~ms}^{-1}$. The reason for this behavior and the discrepancy between the heat transfer coefficients is still under investigation. The measured $C_{e 10 n}$ is at a minimum $\left(0.97 \times 10^{-3}\right)$ at $5 \mathrm{~ms}^{-1}$ but increases with wind speed thereafter consistent with Fairall et al., (2003). The measured $C_{e 10 n}$ oscillate close to its mean value i.e. from $0.9 \times 10^{-3}$ at $7 \mathrm{~ms}^{-1}$ to $1.2 \times 10^{-3}$ at $15 \mathrm{~ms}^{-1}$.

The neutral drag coefficient was noted to increase for wind speed $>5 \mathrm{~ms}^{-1}$ and towards low wind speeds in earlier studies [Smith, 1988; Yelland et al., 1998]. Fairall et al., (2003) observed a rise in $C_{d 10 n}$ for winds $<1 \mathrm{~ms}^{-1}$ and at $20 \mathrm{~ms}^{-1}$ with the minimum value as $1.0 \times 10^{-3}$ at wind speed $3 \mathrm{~ms}^{-1}$. Our calculations show a continuous rise in both bulk and measured $C_{d 10 n}$ with respect to rising $U_{10 n}$. However, we do not have enough data at wind speeds below $3 \mathrm{~ms}^{-1}$ to investigate the behavior at low winds.

Surface waves act as the roughness elements that COARE models using the sea surface roughness length that defines the neutral transfer coefficients. The COARE 3.0 and 3.5 algorithms include parameterizations that model the velocity roughness length as a function of specified wave properties such as significant wave height, wavelength of spectral peak and inverse wave age. However, both versions of COARE have wind- 
speed dependent parameterization of the roughness length that match observations well without wave information. Edson et al., [2013] showed that the wave age varies almost linearly with wind speed over the open ocean, which provides an explanation for why wind-speed and wave-age formulations give similar results.

Here, an attempt is made to investigate the wave age and sea-state dependency of the roughness length using the approach described by Donelan et al., [1993]. This approach normalizes the roughness length by the significant wave height and plots the normalized height against inverse wave age squared. The roughness length for rough flow, $z_{0}^{\text {rough }}$ can be calculated as: $z_{0}^{\text {rough }}=z_{0}-z_{0}^{\text {smooth }}=10 e^{-\kappa / c_{110 n}^{0.5}-}$ $0.11 \mathrm{v} / u_{*}$ [Edson et al., 2013] where $z_{0}^{\text {smooth }}$ is roughness of the ocean when it is aerodynamically smooth, $z_{0}$ is total roughness length, $\kappa$ is von Kármán's constant and $v$ is the kinematic viscosity of air. Previous studies [Smith et al., 1992; Donelan et al., 1993; Dobson et al., 1994; Edson et al., 2013] used this linear approach to explore the association between sea state (specifically wave age) and roughness length:

$$
\frac{z_{0}^{\text {rough }}}{\gamma}=D\left(\frac{u_{*}}{c_{p}}\right)^{2}
$$

Where $D$ is a numerical constant. Eq. (2) is implemented by fitting $z_{0}^{\text {rough }} / \gamma$ to binaveraged values of squared $u_{*} / C_{p}$ as shown in figure 5 . The measurements used in the present analysis range from 6.9 to 30.4 for $C_{p}, 0.75$ to 8.75 for $\gamma, 0.25$ to 8.35 for $\gamma_{w}$ and from 0.02 to $1.6 \mathrm{~ms}^{-1}$ for $u_{*}$. The measurements used to develop COARE 3.5 gave a value of $D=0.09$ using the significant wave height to normalize the roughness length [Edson et al., 2013]. Using linear regression, the values of $D$ are reported as slightly high with values of 0.128 and 0.117 using $\gamma_{w}$ and $\gamma$ to normalize the roughness length in Eq. (2), respectively.

\subsection{Flux variations over mesoscale ocean eddies}

The surface fluxes are convolved with the meteorology (wind speed, air temperature, and humidity) encountered while over the eddies. So, for a small sample, mean fluxes over the sampled eddies may not be representative of the climatological effects of ocean eddies. We have looked at this in two ways. First, we have compared the fluxes in normalized form as a function of the thermal forcing. From the basic bulk flux relationship, we can write,

$$
\overline{w^{\prime} X^{\prime}} / U_{10 n} \cong C_{x 10 n} \Delta X_{10 n}
$$

Thus, we expect a graph of the covariance divided by $U_{10 n}$ to be a linear function of the air-sea difference with a slope given by the transfer coefficient. This is illustrated for the $H_{s}$ and $H_{l}$ in figure 6a. For $H_{s}$, the warm (red symbols) vs cold (blue symbols) eddy is apparent in the sea-air temperature difference. The EC and ID flux estimates cluster 
about the bulk flux line with variability that is typical for 10 -min samples. There is some hint of a high bias. The scatter about the bulk flux line is similar in magnitude to the sensible fluxes, but there is no obvious bias. By removing the velocity forcing factor, this presentation makes clear the effects of the thermodynamic forcing and suggest that the bulk flux calculations give reasonable estimates of the fluxes over the eddies. However, there may be issues with different sampling by bulk fluxes (which are computed from $T_{s}$ right at the ship) versus the turbulent fluxes measured at $20 \mathrm{~m}$ height that are characterized by an upwind footprint as much as $0.5 \mathrm{~km}$ from the ship. Also, near the edge of a $T_{s}$ gradient, the turbulent fluxes may be driven by a substantially different $T_{s}$ and $q_{s}$.

The second method is through distributions of 10-minute COARE 3.5 bulk fluxes over six atmospheric/oceanic states: voyage including eddies, voyage without eddies, the cold eddy, the warm eddy, no-rain conditions and rainy conditions are shown in figure 6b. Further, table 4 depicts the mean bulk fluxes and flux-related state variables for these six states. It is noted that these forcings are not independent and it is extremely difficult to single out the effect of each forcing with our limited samples. For instance, precipitation events and frontal passages occurred over the mesoscale ocean eddies as well.

The results show that $U_{10}$ is higher by $26.3 \%$ over the warm eddy and lower by $3.6 \%$ over the cold eddy as compared to average voyage values. The average $\tau$ over the warm eddy is higher (mean $0.39 \mathrm{Nm}^{-2}$ ) than that over the cold eddy (mean $0.19 \mathrm{Nm}^{-2}$ ) and the entire voyage (mean $0.21 \mathrm{Nm}^{-2}$ ). Compared with the overall mean for the voyage $\left(1.5 \times 10^{-3}\right)$, the mean $C_{d 10 n}$ is higher over the warm eddy $\left(1.8 \times 10^{-3}\right)$ and lower over the cold eddy $\left(1.4 \times 10^{-3}\right)$ as reported by White and Annis (2003) as well. The air-sea temperature difference, $\Delta T$ ranges from $-3.2^{\circ} \mathrm{C}$ to $3.9^{\circ} \mathrm{C}$ over the cold eddy and from $7.7^{\circ} \mathrm{C}$ to $1.8^{\circ} \mathrm{C}$ over the warm eddy. Mean $\gamma_{w}$ is higher by $33 \%$ over the warm eddy and by $19 \%$ during rainy conditions as compared to the average voyage values. Further, the mean net enthalpy flux $\left(H_{S}+H_{l}\right)$ over the warm eddy $\left(\sim 141.2 \mathrm{Wm}^{-2}\right)$ is nearly 15 times greater in magnitude than over the cold eddy $\left(\sim-9.14 \mathrm{Wm}^{-2}\right)$. The mean net hourly airsea flux for the voyage without eddies is $80.4 \mathrm{Wm}^{-2}$, higher than for the voyage with eddies $\left(71.6 \mathrm{Wm}^{-2}\right.$ ). Despite the increase in wind stress, both $H_{s}$ and $H_{l}$ (mean $8.9 \mathrm{Wm}^{-}$ 2 and $37.7 \mathrm{Wm}^{-2}$ respectively) decrease during rain events as compared to no-rain conditions (mean $H_{s}$ as $13.7 \mathrm{Wm}^{-2}$ and $H_{l}$ as $70.4 \mathrm{Wm}^{-2}$ ) during the voyage. Conclusively, $\gamma_{w}, \tau, H_{s}$ and $H_{l}$ increase by approximately $33 \%, 89 \%, 187 \%$ and $79 \%$, respectively, over the warm eddy and decrease by approx. 3\%, 5\%, 223\% and 90\% respectively over the cold eddy as compared to the mean voyage values.

\subsection{Rain heat flux $\left(H_{r}\right)$ variations}


Low-intensity rainfall events $\left(<5 \mathrm{mmh}^{-1}\right)$ accounted for $80.7 \%$ of total frequency of rainfall events, compared with $1.5 \%$ of heavy $\left(5-10 \mathrm{mmh}^{-1}\right)$ and $0.7 \%$ of very heavy (>10 $\mathrm{mmh}^{-1}$ ) rainfall events. On average, $H_{r}$ remains largely positive and equal to $H_{s}$ and much smaller than $H_{l}$ (figure 7 ). The positive $H_{r}$ indicates that the raindrops are colder than $T_{s}$, transporting heat from ocean to atmosphere i.e. cooling the ocean surface [Gosnell et al., 1995]. Over the cold eddy, it has been found to be mostly negative along with both $H_{s}$ and $H_{l}$.

It is observed that although $H_{r}$ remains small $\left(\sim 2 \mathrm{Wm}^{-2}\right)$ for low intensity rainfall $(<5$ $\mathrm{mmh}^{-1}$ ), it increases with increasing rain rate and becomes large, nearly of the order of the $H_{l}$ or larger $\left(>100 \mathrm{Wm}^{-2}\right)$ during the infrequent heavy rainfall events $\left(>20 \mathrm{mmh}^{-}\right.$

$\left.{ }^{1}\right)$ over the SO as shown in figure 7. $H_{r}$ varied considerably over the cold and warm eddies. Over the cold eddy, $H_{r}$ remains small $<10 \mathrm{Wm}^{-2}$ with average $-1.5 \mathrm{Wm}^{-2}$ irrespective of the rain rate. However, over the warm eddy, $H_{r}$ is much higher (mean $111 \mathrm{Wm}^{-2)}$ for rain rates greater than $10 \mathrm{mmh}^{-1}$. For rain rates greater than $20 \mathrm{mmh}^{-1}$, $H_{r}$ becomes even larger than $H_{l}$ with a difference of more than $20 \mathrm{Wm}^{-2}$. A closer analysis reveals that $T_{a}$ remains lower than $T_{s}$ over the warm eddy during both rain and no-rain conditions. The negative $H_{l}$ occurs when $T_{a}>T_{s}$ and $q_{a}>q_{s}$ leading to fog conditions and negative $H_{r}$ (i.e. lower $T_{s}$ than temperature of raindrops transporting heat into the ocean). Negative values of $H_{l}$ were observed $43 \%$ of the time when the ship was over the cold eddy compared with only $6 \%$ of the time for the entire voyage. These results indicate that the cold eddy (warm eddy, respectively) is contributing to net heat gain (net heat loss, respectively) to the ocean even during precipitation events, the magnitude of which increases with increasing rain rate.

\subsection{Marine atmospheric boundary layer stability and flux variability}

Static stability affects the convection in the boundary layer and can be used in conjunction with the momentum and heat flux variability to characterize the marine atmospheric boundary layer stability [Archer et al., 2016]. As per Monin Obukhov Similarity Theory, the Monin-Obukhov dimensionless stability parameter, $\xi$ is defined as $z / L$ where $z$ is the height of measurement and $L$ is the Obukhov length, and plays a significant role in the computation of surface fluxes [Bradley and Fairall, 2006]. Here, we report the variability of fluxes in different stability regimes. It determines the stratification in the surface layer [Foken, 2008] with the following classification used in this paper: (i) $\xi<-1$ very unstable, (ii) $-1<\xi<-0.005$ unstable, (iii) $-0.005<\xi<0$ unstable close to neutral, (iv) $0<\xi<0.005$ stable close to neutral, (v) $0.005<\xi<1$ stable, (vi) $\xi>1$ very stable. The values of stability parameter during the voyage are mostly concentrated between -1 and -0.005 , corresponding to an unstable atmosphere, promoting forced convection. This is not unusual over the ocean surface where the sea surface is generally warmer than the air. Mostly stable stratification is dominant over the cold eddy as the air is often warmer than the ocean (mean $~ 0.7$ ${ }^{\circ} \mathrm{C}$ ), in contrast to over the warm eddy where $\Delta T$ is found to be lowest (i.e., where the 
air-sea temperature difference was $-2.12^{\circ} \mathrm{C}$ ) causing unstable stratification. It is also noticeable that unstable conditions prevail irrespective of rainy or non-rainy conditions. The stable stratification is also observed in the warm sector of extratropical cyclones. The stability parameter, $\xi$ is observed to be mostly negative (average -0.14) implying unstable stratification during pre-conditions but in the warm sector or midstconditions stable stratification (average 0.24 ) is observed which again reverts to unstable (average - 0.36 ) in the post- frontal conditions.

Sixty-three percent of the total $\tau$ samples are concentrated at $-1<\xi<-0.005$ with a mean of $0.22 \mathrm{Nm}^{-2}$. However, mean $\tau$ peaks $\left(0.4 \mathrm{Nm}^{-2}\right)$ during stable close to neutral conditions i.e. when $0<\xi<0.005$. These peaks correspond to warm sector of the extratropical cyclones during cold eddy sampling. Further, both $H_{s}$ and $H_{l}$ peak with means of $26.8 \mathrm{Wm}^{-2}$ and $90.2 \mathrm{Wm}^{-2}$, respectively during unstable stratification when $1<\xi<-0.005$. We note that the sample size is small $(<1 \%)$ during stable stratification when $\xi>1$. During stable stratification i.e. $\xi>0.005, H_{s}$ is strictly negative (mean -18.7 $\mathrm{Wm}^{-2}$ ) and $H_{l}$ is mostly negative with a mean of $-9.3 \mathrm{Wm}^{-2}$ i.e. directed towards the ocean.

\subsection{Extratropical cyclonic storms and flux variability}

The location and timing of surface heat and moisture fluxes affect the cyclone evolution and development [Persson et al., 2005, 2008]. Figure 9 displays $H_{s}, H_{l}$ and $\tau$ distributions during pre-, post- and midst- conditions over the passage of six extratropical cyclones during the voyage. As concluded from the six cases, mean $\Delta T$ changes from $-0.88^{\circ} \mathrm{C}$ during pre- conditions to $0.75^{\circ} \mathrm{C}$ during midst- conditions followed by a sharp decrease of $-2.08^{\circ} \mathrm{C}$ after the cold front arrives (figures not included). Mean $\gamma_{w}$ is observed to negligibly decrease (by $<1 \%$ ) from pre- to midstconditions but increases behind the front by $13.8 \%$. Approximately 1-hour lagged ocean response to the storms is observed, however, the pattern of lagged $\gamma_{w}$ does not differ signifcantly.

$U_{10}$ and $\tau$ increase during midst- conditions as compared to pre-conditions and then decrease in post- conditions in most of the cases. Mean $\tau$ increases from $0.18 \mathrm{Nm}^{-2}$ in pre- conditions to $0.3 \mathrm{Nm}^{-2}$ in the midst- and then falls to $0.27 \mathrm{Nm}^{-2}$. Despite the increase in $U_{10}$, both $H_{s}$ and $H_{l}$ values decline significantly during midst- conditions. The reduction in $H_{s}$ is due to a rise in $T_{a}$, which affects and sometime changes the sign of $\Delta T$. Likewise, the reduction of $H_{l}$ is due to moistening in the warm sector. The mean air-sea specific humidity difference, $\Delta q$ increases from -1.8 to -0.32 (i.e., the air is moistening towards saturation with respect to the surface value) in warm sector then decreases to -2.8 during post- conditions. At times, the moistening causes the surface layer to saturate leading to fog formation. The heat fluxes rise subsequently following the passage of the cold front and a dip in $T_{a}$ (mean $7.8^{\circ} \mathrm{C}$ in post-). The mean $H_{s}$ and $H_{l}$ reach a minimum in the midst- conditions with means of -13.4 and $13.1 \mathrm{Wm}^{-2}$, respectively. The fluxes rise dramatically (mean 27.2 and $98.2 \mathrm{Wm}^{-2}$, respectively) 
behind the cold front. The minimum $H_{s}$ and $H_{l}$ values in the midst- are observed over the cold eddy (31 March and 04 April). Conclusively, an increase in $\tau$ ( $\sim 62 \%$ average) and a decline in $H_{s}(\sim 235 \%)$ and $H_{l}(\sim 79 \%)$ is noted in the warm sector, compared to pre-storm conditions. This pattern reverses behind the cold front as $\tau$ decreases by $\sim 11 \%$ but $H_{s}$ and $H_{l}$ increase by $\sim 303 \%$ and $\sim 647 \%$ respectively, compared to the warm sector values as observed in the present study. In the warm sector, $\tau$ ranged from 0.01$1.07 \mathrm{Nm}^{-2}$ which is less intense than that observed over the Atlantic Ocean[Persson et al., 2008]. However, heat fluxes show large variations in the warm sector with $H_{s}$ of $91-103 \mathrm{Wm}^{-2}$ and $H_{l}$ of $-105-180 \mathrm{Wm}^{-2}$.

\section{Discussion}

[1] COARE 3.5 model performance is assessed by comparing direct and model derived neutral transfer coefficients as a function of 10-m neutral wind speed. Due to limited sample size, we cannot address the variability of coefficients at either low $\left(<3 \mathrm{~ms}^{-1}\right)$ or high $\left(>20 \mathrm{~ms}^{-1}\right)$ wind speeds. $C_{e 10 n}$ measurements show limited variability with winds speed, which is consistent with DeCosmo et al., [1996], Persson et al., [2005] and COARE model. Although $C_{h 10 n}$ does show an increase with wind speed above $7 \mathrm{~ms}^{-1}$ as with Persson et al., [2005], the increase is significantly larger and the results are suspect due to issues with sonic temperature as discussed in Appendix B. In COARE 3.5 , both $C_{e 10 n}$ and $C_{h 10 n}$ are assumed to be the same. However, these results indicate that $C_{e 10 n}$ and $C_{h 10 n}$ behave differently and should be studied further.

[2] The sea-state dependency of the momentum flux is analysed through the sea surface roughness length and wave-age parameterization as given in eq. (2). A slightly higher value of the numerical constant, $D$ is noted as compared to 0.09 in COARE 3.5, which might affect the evaluation of the Charnock coefficient. Edson et al. (2013) found $D=0.09$ to be a good fit for all sea states. However, this value might be higher for a sea state dominated by younger waves and vice versa. During CAPRICORN 2016, a fully developed sea with an inverse wave age of less than 0.03 was common over the SO (61\% of all times). A mixed sea state composed of both wind sea waves and swell is frequent between $43^{\circ}-53^{\circ} \mathrm{S}$ of the SO [Hanley et al., 2011]. Consequently, one single $D$ value might not be representative of total wave influence on surface stress or universally applicable.

[3] Despite nominal changes in $U_{10}$ and $\tau$ over the cold eddy, as compared to the mean voyage values, a significant decrease is noted in mean heat flux values. Over the warm eddy, on the other hand, a significant increase is observed in mean $\tau, H_{s}$ and $H_{l}$. Modifications in near surface winds and wind stress due to mesoscale sea surface temperature anomalies have been well documented [White and Annis, 2003; Chelton, 2004; Park et al., 2006; Frenger et al., 2013]. However, the magnitudes of changes in surface winds, wind stress and heat fluxes over the warm and cold eddy measurably differ. Surface heat fluxes over isolated eddies in the SO region are also observed to be far stronger than the climatological flux means in the energetic regions in the South 
Atlantic Ocean [Bôas et al., 2015]. These observations of large fluxes over the SO mesoscale eddies might be governed by the sea surface temperature anomaly arising from the ocean polar front in the SO as well as lifetime and evolution stage of the ocean eddy. During the sampling, the cold eddy had reached past its mature stage and had entered its decay phase impacting its amplitude Patel et al., [2019]. The warm eddy, however, was a short-lived eddy and shifted its centre quickly as per the altimetry observations. Thus, precise quantification of the air-sea fluxes over the lifecycle of mesoscale eddies in the SO at high spatiotemporal resolution might fill the potential gaps in the uncertainties in the atmospheric heat budget.

[4] Although duration limited, $H_{r}$ increases with rain rate and becomes of the order of $H_{s}$ and higher for rain rate $>5 \mathrm{mmh}^{-1}$. $H_{r}$ also becomes as large as $H_{l}$ and higher for rain rate $>20 \mathrm{mmh}^{-1}$. Higher mean rain rate and mean $H_{r}$ are observed over the warm eddy. However, high rain rates are rare and light precipitation $\left(<1.5 \mathrm{mmh}^{-1}\right)$ dominates the SO as observed by Wang et al., [2015]. The region is also renowned for secondary ice production as observed in previous studies [Huang et al., 2017; Mace and Protat, 2018] which might produce much higher $H_{r}$ if hail were to reach the ocean. This aspect remains unaccounted for in the COARE 3.5 model.

[5] Stable stratification is not a common occurrence over the SO sector and was primarily observed over the cold eddy and in the warm sector of frontal passages. $\tau$ and $U_{10}$ are highest during stable close to neutral regime $(0<\xi<0.005)$ whereas $H_{s}$ and $H_{l}$ peak in the weakly unstable regime $(-1<\xi<-0.005)$. Enhancement in turbulence due to detached atmospheric eddies has been observed [Smedman et al., 2007; Sahlee et al., 2008] under convective conditions when $L<-150 \mathrm{~m}$ over both land and sea. An alternate flux model over sea was also suggested by Rutgersson et al., [2007] considering this regime. However, our results suggest that sensible and latent heat fluxes peak when $L<-20 \mathrm{~m}$ (when $\mathrm{z}=21 \mathrm{~m}$ ) or $L<-10 \mathrm{~m}$ (when $\mathrm{z}=10 \mathrm{~m}$ ) in the SO. Thermal or moisture roughness length did not corroborate to this peak in the heat fluxes.

[6] The ocean-atmosphere state and the extratropical storms in the SO are distinct from those of the North Atlantic and North Pacific (e.g., Hoskins and Hodges, [2005]; Huang et al., [2015]). In general, the wintertime cold air outbreak events experienced in the northern hemisphere are larger and stronger Fletcher et al., [2016]. The momentum and heat flux variations in the warm sector and post-frontal regimes of the extratropical cyclones during the voyage are in accordance with the results from Persson et al. (2005) over the Atlantic Ocean. However, the rise in $q_{a}$ did cause negative $H_{l}$ in all 6 cases contrary to Persson et al. (2005). The heat flux variations are also more intense than those observed by Persson et al. (2008) in the warm sector. Although heat fluxes always decrease in the warm sector, they remain almost always negative over the cold eddy despite similar changes in $T_{a}$ and $q_{a}$ in all 6 cyclones. These results suggest that the extratropical cyclones in conjunction with the mesoscale ocean eddies have a significant compound effect on the surface heat fluxes. Previous 
studies have suggested a probable coupling between mesoscale SST anomalies and synoptic storms [Small et al., 2008; Su et al., 2018] affecting air-sea fluxes. While surface heat fluxes are crucial in cyclogenesis [Yokoyama and Yamamoto, 2019], the cyclonic development stage might modulate flux variability too. However, more observations are needed to segregate individual processes.

\section{Conclusion}

The CAPRICORN 2016 experiment provided unprecedented observations of air-sea interaction over the lower latitudes of the Southern Ocean from Hobart $\left(43^{\circ} \mathrm{S}\right)$ to the edge of the Subantarctic Front near $53^{\circ} \mathrm{S}$. Although the voyage lasted only for a month (March 14 - April 15, 2016), it was the first time such high-quality air-sea flux observations were collected using NOAA PSD flux system over this sector of the Southern Ocean. The experiment facilitated the performance assessment of COARE

3.5 bulk parameterization model over the Southern Ocean region. Prior to this, the NOAA flux system was deployed during the Southern Ocean Gas Exchange Experiment (GasEx) which was carried out in the southwest Atlantic sector of the Southern Ocean $\left(50^{\circ} \mathrm{S}, 40^{\circ} \mathrm{W}\right)$ in 2008 (Edson et al., 2011).

Despite the limited observations, our analysis reveals that the ocean and atmosphere processes often cannot be isolated from one another. Nevertheless, our study offers fresh insights into the air-sea interaction processes in the Southern Ocean and provides some fundamental basics for evaluating atmosphere and ocean models over a poorly observed but climatically important region.

\section{Acknowledgement}

This research is supported by ARC Centre of Excellence for Climate System Science (grant DP150102894). PSD participation was supported by NOAA's Climate Program Office, Climate Observation Division. All the data used are listed in the references. The authors wish to thank the CSIRO Marine National Facility (MNF) for its grant of sea time on Investigator and associated personnel, scientific equipment, and data management. Finally, we would like to acknowledge the crucial roles played by Tom Trull (CSIRO), the lead chief scientist, Tegan Sime, the MNF voyage manager, and the Investigator crew to make this research voyage a success. The first author thanks the editor, reviewer James Edson and one anonymous reviewer for their extensive and constructive comments on an earlier version of this manuscript, which had helped us to improve the quality of this research article. CAPRICORN 2016 data archive is available from NOAA (gov.noaa.nodc:0170257). 


\section{Appendices}

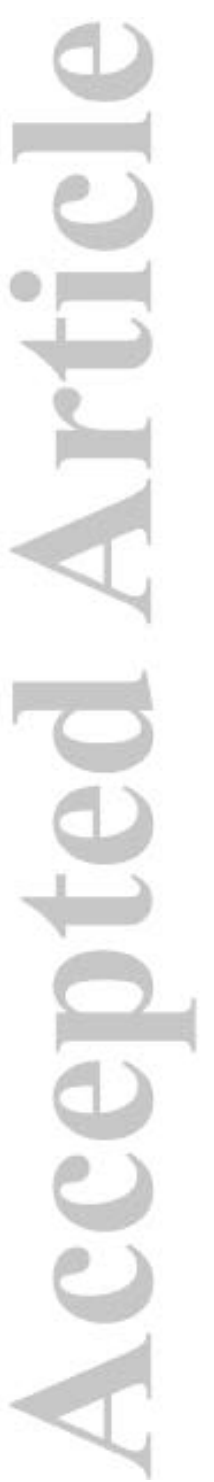




\section{Appendix A: List of variables}

$\gamma$ significant wave height of full sea, $\mathrm{m}$ $\gamma_{w}$ significant wave height of wind sea waves, $\mathrm{m}$

$\gamma_{s} \quad$ significant wave height of swell waves, $\mathrm{m}$

$u_{*}$ friction velocity, $\mathrm{ms}^{-1}$

$C_{p}$ phase speed of dominant waves, $\mathrm{ms}^{-}$ 1

$T_{p}$ spectral peak period, $\mathrm{s}$

$g$ gravitational acceleration, $\mathrm{ms}^{-2}$

$U_{10} 10-\mathrm{m}$ wind speed, $\mathrm{ms}^{-1}$

$U_{10 n} 10-m$ neutral wind speed, $\mathrm{ms}^{-1}$

$F_{w}$ separation or cut-off frequency

$t$ time, $\mathrm{s}$

$P$ pressure, $\mathrm{hPa}$

$T_{a}$ air temperature, ${ }^{\circ} \mathrm{C}$

$T_{s}$ sea surface temperature, ${ }^{\circ} \mathrm{C}$

$W$ wind direction, radian

$\rho$ air density, $\mathrm{kgm}^{-3}$

$L_{v}$ latent heat of vaporization, $\mathrm{Jkg}^{-1}$

$C_{d}$ drag coefficient

$C_{h}$ sensible heat transfer coefficient or Stanton number

$C_{e}$ latent heat transfer coefficient or Dalton number

$c_{p}$ isobaric specific heat of air, $\mathrm{Jkg}^{-1} \mathrm{~K}^{-1}$

$\theta$ potential temperature, $\mathrm{K}$

$q_{a}$ air specific humidity, $\mathrm{gkg}^{-1}$

$q_{s}$ sea surface saturation specific humidity, $\mathrm{gkg}^{-1}$

$\Delta q$ sea surface saturation and air specific humidity difference, $\mathrm{gkg}^{-1}$

$H_{s}$ sensible heat flux, $\mathrm{Wm}^{-2}$

$H_{l}$ latent heat flux, $\mathrm{Wm}^{-2}$

$H_{r}$ rain heat flux, $\mathrm{Wm}^{-2}$

$\tau$ wind stress or momentum, $\mathrm{Nm}^{-2}$

$w$ vertical wind velocity, $\mathrm{ms}^{-1}$

$U_{g}$ gustiness, $\mathrm{ms}^{-1}$

$G$ gustiness factor, $\mathrm{ms}^{-1}$

$R$ rain rate, $\mathrm{mmh}^{-1}$

$C_{p w}$ specific heat capacity of liquid water, $\mathrm{Jkg}^{-1} \mathrm{~K}^{-1}$

$\alpha_{w}$ Clausius- Clayperon wet-bulb factor
$\Delta T$ air and sea surface temperature difference, ${ }^{\circ} \mathrm{C}$

$B_{o}$ bulk Bowen ratio

$z_{0}^{\text {rough }}$ roughness length for rough flow, $\mathrm{m}$

$z_{0}^{\text {smooth }}$ roughness length for smooth flow, $m$

$z_{0}$ total roughness length, $\mathrm{m}$

$\kappa$ von Kármán's constant,

dimensionless

$v$ kinematic viscosity of air, $\mathrm{m}^{2} \mathrm{~s}^{-1}$

$Z$ height, $\mathrm{m}$

$L$ Obukhov length, $\mathrm{m}$

$\xi$ Monin-Obukhov stability parameter, dimensionless 


\section{Appendix B: Temperature and Humidity Variance Spectra and Inertial Dissipation (ID) method}

Inertial-dissipation (ID) flux estimates are based on the Monin-Obukhov Similarity scaling relationship between the turbulent structure function parameter, $C_{x}^{2}$, for the variable, $X(u, v, w, T, q)$ and MOS scaling parameter, $x_{*}$,

$$
C_{x}^{2}=z^{-2 / 3} x_{*}^{2} f_{x}(z / L)
$$

where $x_{*}=-\overline{w^{\prime} x^{\prime}} / \sqrt{\overline{-w^{\prime} u^{\prime}}}$ and $f_{x}(z / L)$ is describes the stability dependence $(L$ is the $\mathrm{MO}$ length). The structure function values are obtained from fit to the frequency spectrum of $X$. In the inertial subrange, the spectrum is expected to obey

$$
S_{x}(f)=0.25 C_{x}^{2}\left(\frac{U_{r}}{2 \pi}\right)^{2 / 3} f^{-5 / 2}
$$

where 0.25 is a mathematical constant and $U_{r}$ is the relative wind speed. The inertial subrange occurs frequencies where the turbulent fluctuations are approximately isotropic, usually frequencies greater than $f_{i}=0.5 z / U_{r}$ [Kaimal et al., 1972], where $z$ is the height of the sensor. Above $f_{i}$ the spectrum follows the $-5 / 3$ power law until the dissipation scale is reached (usually $f>100 \mathrm{~Hz}$ ).

We can use observed atmospheric spectra with (B2) to estimate $C_{x}^{2}$ and (B1) is used to compute $x *$ and the flux is given by

$$
\overline{w^{\prime} x^{\prime}}=-x_{*} u_{*}
$$

The determination of $C_{x}^{2}$ is affected by experimental issues associated with the turbulent sensors: noise, spectral distortion, path averaging, and internal processing/filtering. Path averaging and lowpass filtering typically cause the spectrum to be distorted at frequencies below the Nyquist frequency. So, the spectrum will often decrease faster than $f^{5 / 3}$ approaching the Nyquist frequency. In condition of weak forcing, the spectrum may decline until the broadband noise level of the sensor is reach and then it will flatten. With sonic anemometers, this rarely happens for $S_{u}$ $S_{v}$, and $S_{w}$ but occurs occasionally for $S_{q}$ and is common for $S_{t}$. In order to improve the rendition of the inertial subrange, we subtract a white noise level from $S_{t}$. However, if the noise level is significant at $f_{i}$, then estimates of the temperature structure function become uncertain.

It turns out that the Metek sonic anemometer we used on CAPRICORN 2016 has some undesirable behavior in low signal conditions. To illustrate this, we show mean temperature spectra from the sonic anemometer and mean humidity spectra from the LICOR hygrometer. Fig. B1 shows mean temperature and humidity spectra for conditions with strong forcing of temperature fluctuations (large sea-air temperature difference). Both $T$ and $q$ show substantial regions with the expected inertial-subrange 
slope; $f_{i}$ is on the order of $0.2 \mathrm{~Hz}\left(f_{i} z / U_{r}=0.53\right)$. The humidity spectrum shows path averaging beginning about $1.5 \mathrm{~Hz}$. The raw temperature spectrum does not show much of a $-5 / 3$ region, but with the noise removed $\left(S_{t}\right.$-noise), the shape is similar to humidity. This is indicated by normalizing each spectrum by its mean structure function values and taking the ratio (lower panel, Fig. B1). Because of surface-layer similarity, this ratio is expected to be near 1.0.

Spectra with weaker forcing are shown in Fig. B2. The humidity spectrum is still well behaved but even the noise-corrected temperature spectrum fails to show a clear $-5 / 3$ region. The ratio given in the lower panel of Fig. B2 indicates problems above $0.2 \mathrm{~Hz}$. Thus, the ID sensible heat flux values become questionable for $\Delta T 10<1.5 \mathrm{C}$. For $\Delta T 10<1$ (not shown), the spectra are unusable.
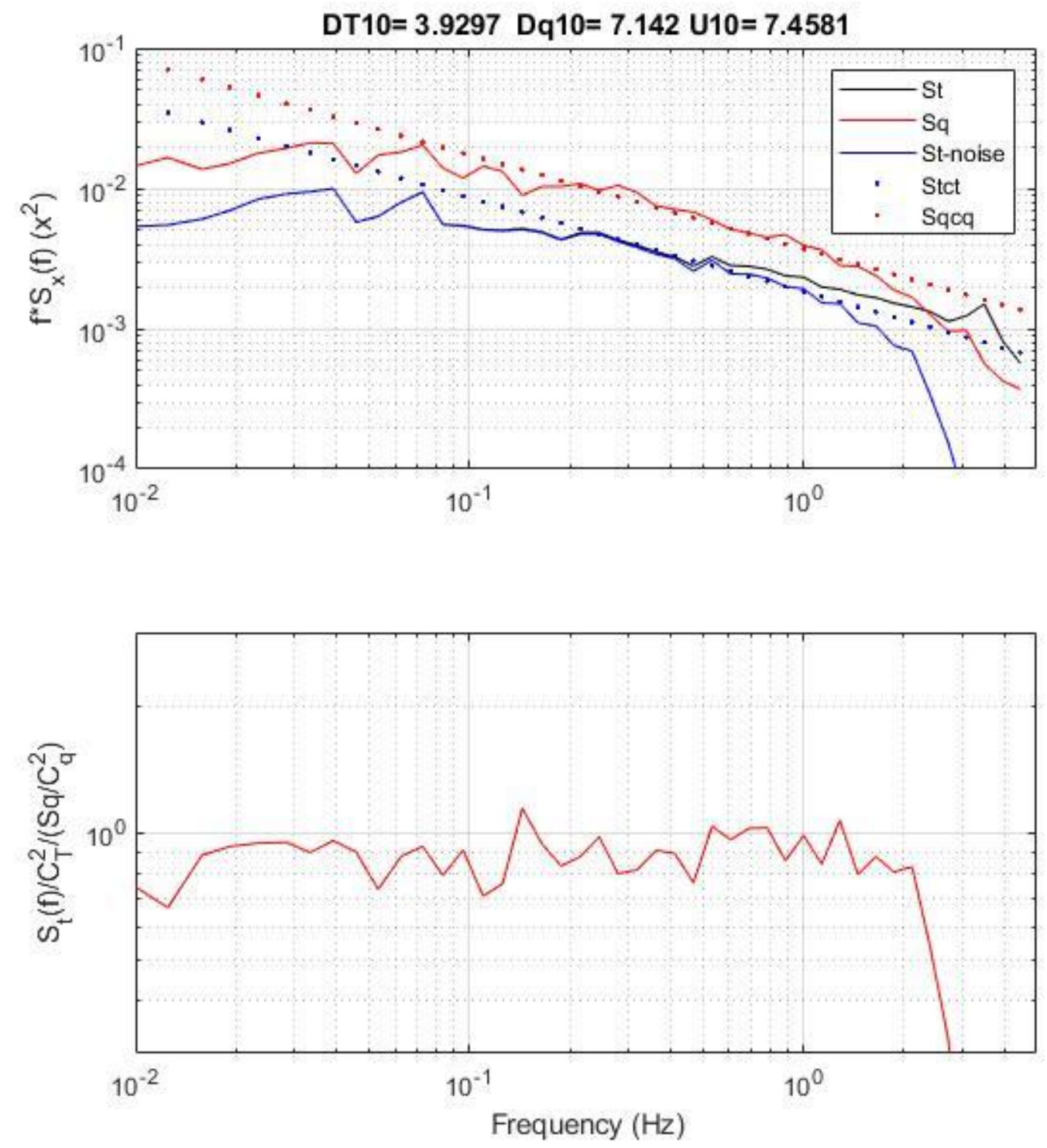

@2019 American Geophysical Union. All rights reserved. 
Figure B1. Upper panel: Average variance spectra for temperature (blue) and humidity (red) for 14 10-minute samples with sea-air temperature difference $\left(\Delta T_{10}\right)$ between 3 and $5 \mathrm{C}$. The dotted lines are (B2) using the mean of our estimated structure function values for the sample. Lower panel; the ratio of the $S_{t} / C_{t}{ }^{2}$ to $S_{q} / C_{q}{ }^{2}$; this ratio should be close to 1.0 .
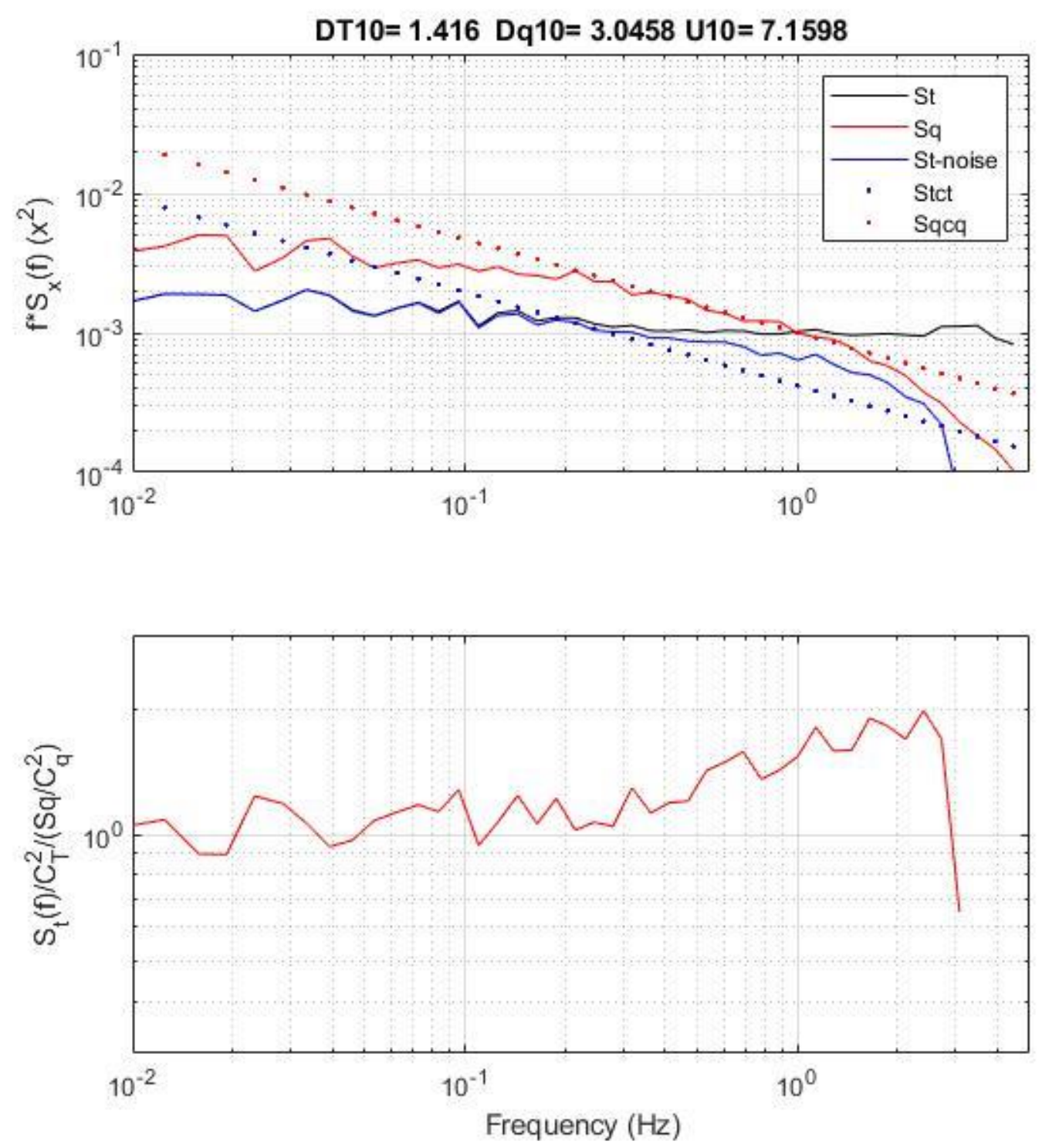

Figure B2. Upper panel: Average variance spectra for temperature (blue) and humidity (red) for 60 10-minute samples with sea-air temperature difference $\left(\Delta T_{10}\right)$ between 1 and $2 \mathrm{C}$. The dotted lines are (B2) using the mean of our estimated structure function values for the sample. Lower panel; the ratio of the $S_{t} / C_{t}{ }^{2}$ to $S_{q} / C_{q}{ }^{2}$; this ratio should be close to 1.0 . 


\section{References}

Andreas, E. L., and E. C. Monahan (2000), The Role of Whitecap Bubbles in Air-Sea Heat and Moisture Exchange, Journal of Physical Oceanography, 30, 433-442, doi:10.1175/1520-0485(2000)030<0433:TROWBI>2.0.CO;2.

Archer, C. L., B. A. Colle, D. L. Veron, F. Veron, and M. J. Sienkiewicz (2016), On the predominance of unstable atmospheric conditions in the marine boundary layer offshore of the U.S. northeastern coast, J. Geophys. Res. Oceans, 120, 33723380, doi:10.1002/2015JC011421. Received.

Bariteau, L., C. Fairall, B. Blomquist, and S. Pezoa (2018), CAPRICORN 2016 Field campaign: surface meteorological data and turbulent fluxes collected from the RV Investigator by the National Oceanographic and Atmospheric Administration (NOAA) in the Indian and South Pacific Oceans from 2016-03-14 to 2016-04-15 (NC, , doi:10.7289/V5Q81BBC.

Beare, R. J. (2007), Boundary layer mechanisms in extratropical cyclones, Quarterly Journal of the Royal ..., 133(October), 503-515, doi:10.1002/qj.

Bôas, A. B. V., O. T. Sato, A. Chaigneau, and G. P. Castelão (2015), The signature of mesoscale eddies on the air-sea turbulent heat fluxes in the South Atlantic Ocean, Geophysical Research Letters, 42, 1856-1862, doi:10.1002/2015GL063105.1.

Bourassa, M. A. et al. (2013), High-latitude ocean and sea ice surface fluxes: Challenges for climate research, Bulletin of the American Meteorological Society, 94(3), 403-423, doi:10.1175/BAMS-D-11-00244.1.

Bradley, F., and C. Fairall (2006), A guide to making climate quality meteorological and flux measurements at sea, NOAA Technical Memorandum, OAR PSD31(October).

Brunke, M. A., C. W. Fairall, X. Zeng, L. Eymard, and J. A. Curry (2003), Which Bulk Aerodynamic Algorithms are Least Problematic in Computing Ocean Surface Turbulent Fluxes?, Journal of Climate, 16(4), 619-635, doi:10.1175/15200442(2003)016<0619:WBAAAL>2.0.CO;2.

Cerovečki, I., L. D. Talley, and M. R. Mazloff (2011), A comparison of southern ocean air-sea buoyancy flux from an ocean state estimate with five other products, Journal of Climate, 24(24), 6283-6306, doi:10.1175/2011JCLI3858.1.

Chelton, D. B. (2004), Satellite Measurements Reveal Persistent Small-Scale Features in Ocean Winds, Science, 303, 978-983, doi:10.1126/science.1091901. 
Curry, J. A. et al. (2004), Seaflux, Bulletin of the American Meteorological Society, 85(3), 409-424, doi:10.1175/BAMS-85-3-409.

DeCosmo, J., K. B. Katsaros, S. D. Smith, R. J. Anderson, W. A. Oost, K. Bumke, and H. Chadwick (1996), Air-sea exchange of water vapor and sensible heat: The Humidity Exchange Over the Sea (HEXOS) results, Journal of Geophysical Research: Oceans, 101(C5), 12001-12016, doi:10.1029/95JC03796.

Dobson, F. W., S. D. Smith, and R. J. Anderson (1994), Measuring the relationship between wind stress and sea state in the open ocean in the presence of swell, Atmosphere - Ocean, 32(1), 237-256, doi:10.1080/07055900.1994.9649497.

Donelan, M. A., fred W. Dobson, S. D. Smith, and robert J. Anderson (1993), On the Dependence of Sea Surface Roughness on Wave Development, Journal of Physical Oceanography, 25(8), 2143-2149, doi:10.1175/15200485(1995)025<1905:CODOSS>2.0.CO;2.

Dong, S., S. T. Gille, and J. Sprintall (2007), An assessment of the Southern Ocean mixed layer heat budget, Journal of Climate, 20(17), 4425-4442, doi:10.1175/JCLI4259.1.

Drennan, W. M., P. K. Taylor, and M. J. Yelland (2005), Parameterizing the Sea Surface Roughness, Journal of Physical Oceanography, 35(5), 835-848, doi:10.1175/JPO2704.1.

Dupuis, H. (2003), Impact of flow distortion corrections on turbulent fluxes estimated by the inertial dissipation method during the $\mathrm{FETCH}$ experiment on R/V L'Atalante , Journal of Geophysical Research, 108(C3), doi:10.1029/2001jc001075.

Edson, J. B., C. W. Fairall, L. Bariteau, C. J. Zappa, A. Cifuentes-Lorenzen, W. R. McGillis, S. Pezoa, J. E. Hare, and D. Helmig (2011), Direct covariance measurement of CO2gas transfer velocity during the 2008 Southern Ocean Gas Exchange Experiment: Wind speed dependency, Journal of Geophysical Research: Oceans, 116(11), 1-24, doi:10.1029/2011JC007022.

Edson, J. B., V. Jampana, R. a. Weller, S. P. Bigorre, A. J. Plueddemann, C. W. Fairall, S. D. Miller, L. Mahrt, D. Vickers, and H. Hersbach (2013), On the Exchange of Momentum over the Open Ocean, Journal of Physical Oceanography, 43(8), 1589-1610, doi:10.1175/JPO-D-12-0173.1.

Fairall, C. W., J. B. Edson, S. E. Larsen, and P. G. Mestayer (1990), Inertial-Dissipation Air-Sea Flux Measurements: A Prototype System Using Realtime Spectral Computations, Journal of Atmospheric and Oceanic Technology, 7(3), 425-453, doi:10.1175/1520-0426(1990)007<0425:IDASFM>2.0.CO;2.

Fairall, C. W., E. F. Bradley, D. P. Rogers, J. B. Edson, and G. S. Young (1996), Bulk parameterization of air-sea fluxes for Tropical Ocean-Global Atmosphere 
Coupled-Ocean Atmosphere Response Experiment, Journal of Geophysical Research, 101(C2), 3747, doi:10.1029/95JC03205.

Fairall, C. W., A. B. White, J. B. Edson, and J. E. Hare (1997), Integrated shipboard measurements of the marine boundary layer, Journal of Atmospheric and Oceanic Technology, 14(3), 338-359, doi:10.1175/15200426(1997)014<0338:ISMOTM>2.0.CO;2.

Fairall, C. W., E. F. Bradley, J. E. Hare, A. A. Grachev, and J. B. Edson (2003), Bulk parameterization of air-sea fluxes: Updates and verification for the COARE algorithm, Journal of Climate, 16(4), 571-591, doi:10.1175/15200442(2003)016<0571:BPOASF>2.0.CO;2.

Fletcher, J., S. Mason, and C. Jakob (2016), The climatology, meteorology, and boundary layer structure of marine cold air outbreaks in both hemispheres, Journal of Climate, 29(6), 1999-2014, doi:10.1175/JCLI-D-15-0268.1.

Foken, T. (2008), Micrometeorology, edited by C. J. Nappo, Springer-Verlag Berlin Heidelberg.

Frenger, I., N. Gruber, R. Knutti, and M. Münnich (2013), Imprint of Southern Ocean eddies on winds, clouds and rainfall, Nature Geoscience, 6(8), 608-612, doi:10.1038/ngeo1863.

Gilhousen, D. B., and R. Hervey (2002), Improved Estimates of Swell from Moored Buoys, in Ocean Wave Measurement and Analysis, edited by Billy L. Edge and J. M. Hemsley, pp. 387-393.

Gosnell, R., C. W. Fairall, and P. J. Webster (1995), The sensible heat of rainfall in the tropical ocean, Journal of Geophysical Research: Oceans, 100(C9), 18437-18442, doi:10.1029/95JC01833.

Greatbatch, R. J., X. Zhai, C. Eden, and D. Olbers (2007), The possible role in the ocean heat budget of eddy-induced mixing due to air-sea interaction, Geophysical Research Letters, 34(7), 1-5, doi:10.1029/2007GL029533.

Hande, L. B., S. T. Siems, M. J. Manton, and D. Belusic (2012), Observations of wind shear over the Southern Ocean, Journal of Geophysical Research Atmospheres, 117(12), 1-19, doi:10.1029/2012JD017488.

Hanley, K. E., S. E. Belcher, and P. P. Sullivan (2011), A Global Climatology of WindWave Interaction, Journal of Physical Oceanography, 41(9), 1811-1813, doi:10.1175/jpo-d-10-05015.1.

Hausmann, U., and A. Czaja (2012), The observed signature of mesoscale eddies in sea surface temperature and the associated heat transport, Deep-Sea Research Part I: Oceanographic Research Papers, 70, 60-72, doi:10.1016/j.dsr.2012.08.005. 
Hausmann, U., A. Czaja, and J. Marshall (2016), Estimates of air-sea feedbacks on sea surface temperature anomalies in the Southern Ocean, Journal of Climate, 29(2), 439-454, doi:10.1175/JCLI-D-15-0015.1.

Herman, A. (2015), Trends and variability of the atmosphere-ocean turbulent heat flux in the extratropical Southern Hemisphere, Scientific Reports, 5(14900), doi:10.1038/srep14900.

Hoskins, B. J., and K. I. Hodges (2005), A new perspective on Southern Hemisphere storm tracks, Journal of Climate, 18(20), 4108-4129, doi:10.1175/JCLI3570.1.

Huang, Y., A. Protat, S. T. Siems, and M. J. Manton (2015), A-Train observations of maritime midlatitude storm-track cloud systems: Comparing the Southern Ocean against the North Atlantic, Journal of Climate, 28(5), 1920-1939, doi:10.1175/JCLI-D-14-00169.1.

Huang, Y., T. Chubb, D. Baumgardner, M. deHoog, S. T. Siems, and M. J. Manton (2017), Evidence for secondary ice production in Southern Ocean open cellular convection, Quarterly Journal of the Royal Meteorological Society, 143(704), 1685-1703, doi:10.1002/qj.3041.

Jiang, C., S. T. Gille, J. Sprintall, K. Yoshimura, and M. Kanamitsu (2012), Spatial variation in turbulent heat fluxes in Drake Passage, Journal of Climate, 25(5), 1470-1488, doi:10.1175/2011JCLI4071.1.

Kaimal, J. C., J. C. Wyngaard, Y. Izumi, and O. R. Coté (1972), Spectral characteristics of surface-layer turbulence, Quarterly Journal of the Royal Meteorological Society, 98(417), 563-589, doi:10.1002/qj.49709841707.

Kawai, Y., and A. Wada (2007), Diurnal sea surface temperature variation and its impact on the atmosphere and ocean: A review, Journal of Oceanography, 63(5), 721-744, doi:10.1007/s10872-007-0063-0.

Large, W. G., and S. Pond (1981), open ocean momentum flux measurements in moderate to strong winds, Journal of Physical Oceanography, 11, doi:10.1175/1520-0485(1981)011<0324:OOMFMI>2.0.CO;2.

Large, W. G., and S. Pond (1982), Sensible and Latent Heat Flux Measurements over the Ocean, Journal of Physical Oceanography, 12(5), 464-482, doi:10.1175/1520-0485(1982)012<0464:SALHFM>2.0.CO;2.

Liu, J., T. Xiao, and L. Chen (2011), Intercomparisons of air-sea heat fluxes over the Southern Ocean, Journal of Climate, 24(4), 1198-1211, doi:10.1175/2010JCLI3699.1.

Mace, G. G. J., and A. Protat (2018), Clouds over the Southern Ocean as observed from the R/V investigator during CAPRICORN. Part I: Cloud occurrence and phase partitioning, Journal of Applied Meteorology and Climatology, 57(8), 1783-1803, doi:10.1175/JAMC-D-17-0194.1. 
Messager, C., S. Speich, and E. Key (2012), Marine atmospheric boundary layer over some Southern Ocean fronts during the IPY BGH 2008 cruise, Ocean Science, 8(6), 1001-1023, doi:10.5194/os-8-1001-2012.

Morrow, R., J. Church, R. Coleman, D. Chelton, and N. White (1992), Eddy momentum flux and its contribution to the Southern Ocean momentum balance, Nature, 360, 40-46.

O'Neill, L. W., D. B. Chelton, and S. K. Esbensen (2003), Observations of SST-induced perturbations of the wind stress field over the Southern Ocean on seasonal timescales, Journal of Climate, 16(14), 2340-2354, doi:10.1175/2780.1.

Olbers, D., J. Willebrand, and C. Eden (2012), The Circulation of the Southern Ocean, in Ocean Dynamics, pp. 1-704, Springer-Verlag Berlin Heidelberg.

Park, K. A., P. Cornillon, and D. L. Codiga (2006), Modification of surface winds near ocean fronts: Effects of Gulf Stream rings on scatterometer (QuikSCAT, NSCAT) wind observations, Journal of Geophysical Research: Oceans, 111(3), 1-19, doi:10.1029/2005JC003016.

Patel, R. S., H. E. Phillips, P. G. Strutton, A. Lenton, and J. Llort (2019), Meridional Heat and Salt Transport Across the Subantarctic Front by Cold-Core Eddies, Journal of Geophysical Research: Oceans, 124(2), 981-1004, doi:10.1029/2018JC014655.

Persson, P. O. G., J. E. Hare, C. W. Fairall, and W. D. Otto (2005), Air-sea interaction processes in warm and cold sectors of extratropical cyclonic storms observed during FASTEX, Quarterly Journal of the Royal Meteorological Society, 131(607), 877-912, doi:10.1256/qj.03.181.

Persson, P. O. G., J. E. Hare, L. B. Nance, B. Walter, C. Noaa, and E. Psd (2008), Impact of Air-Sea Interactions on Extra-Tropical Cyclones, in ECMWF Workshop on Ocean-Atmosphere Interactions, pp. 123-146.

Richter, D. H., and P. P. Sullivan (2014), The Sea Spray Contribution to Sensible Heat Flux, Journal of the Atmospheric Sciences, 71(2), 640-654, doi:10.1175/JAS-D-130204.1.

Rutgersson, A., B. Carlsson, and A. S. Smedman (2007), Modelling sensible and latent heat fluxes over sea during unstable, very close to neutral conditions, BoundaryLayer Meteorology, 123(3), 395-415, doi:10.1007/s10546-006-9150-9.

Sahlee, E., A.-S. Smedman, U. Hogstrom, and A. Rutgersson (2008), Reevaluation of the Bulk Exchange Coefficient for Humidity at Sea during Unstable and Neutral Conditions, J. Physical Oceanography, 38(1), 257-272, doi:10.1175/2007JPO3754.1.

Schulz, E. W., S. A. Josey, and R. Verein (2012), First air-sea flux mooring measurements in the Southern Ocean, Geophysical Research Letters, 39(16), 1- 
9, doi:10.1029/2012GL052290.

Slonaker, R. L., and M. L. van Woert (1999), Atmospheric moisture transport across the Southern Ocean via satellite observations, Journal of Geophysical Research, 104(D8), 9229-9249, doi:10.1029/1999JD900045.

Small, R. J., S. P. DeSzoeke, S. P. Xie, L. O’Neill, H. Seo, Q. Song, P. Cornillon, M. Spall, and S. Minobe (2008), Air-sea interaction over ocean fronts and eddies,

Dynamics of Atmospheres and Oceans, 45, 274-319, doi:10.1016/j.dynatmoce.2008.01.001.

Smedman, A.-S., U. H. ogstr“ Om, E. Sahl', and C. Johansson (2007), Critical reevaluation of the bulk transfer coefficient for sensible heat over the ocean during unstable and neutral conditions, Quarterly Journal of the Royal ..., 133(October), 937-948, doi:10.1002/qj.

Smith, S. D. (1988), Coefficients for sea surface wind stress, heat flux, and wind profiles as a function of wind speed and temperature, Journal of Geophysical Research: Oceans, 93(C12), 15467-15472, doi:10.1029/JC093iC12p15467.

Smith, S. D. et al. (1992), Sea surface wind stress and drag coefficients: The HEXOS results, Boundary-Layer Meteorology, 60(1-2), 109-142.

Song, X., and L. Yu (2012), High-latitude contribution to global variability of air-sea sensible heat flux, Journal of Climate, 25(10), 3515-3531, doi:10.1175/JCLI-D-1100028.1.

Su, Z., J. Wang, P. Klein, A. F. Thompson, and D. Menemenlis (2018), Ocean submesoscales as a key component of the global heat budget, Nature Communications, 9(1), 1-8, doi:10.1038/s41467-018-02983-w.

Trenberth, K. E., and J. T. Fasullo (2010), Simulation of present-day and twenty-firstcentury energy budgets of the southern oceans, Journal of Climate, 23(2), 440454, doi:10.1175/2009JCLI3152.1.

Trull, T. et al (2016), RV Investigator Voyage Summary Voyage, Hobart.

Wang, Z., S. T. Siems, D. Belusic, M. J. Manton, and Y. Huang (2015), A climatology of the precipitation over the Southern Ocean as observed at Macquarie Island, Journal of Applied Meteorology and Climatology, 54(12), 2321-2337, doi:10.1175/JAMC-D-14-0211.1.

White, W. B., and J. L. Annis (2003), Coupling of Extratropical Mesoscale Eddies in the Ocean to Westerly Winds in the Atmospheric Boundary Layer, Journal of Physical Oceanography, 33(5), 1095-1107, doi:10.1175/15200485(2003)033<1095:COEMEI>2.0.CO;2.

Yelland, M. J., B. I. Moat, P. K. Taylor, R. W. Pascal, J. Hutchings, and V. C. Cornell (1998), Wind Stress Measurements from the Open Ocean Corrected for Airflow 
Distortion by the Ship, Journal of Physical Oceanography, 28(7), 1511-1526, doi:10.1175/1520-0485(1998)028<1511:WSMFTO>2.0.CO;2.

Yokoyama, Y., and M. Yamamoto (2019), Influences of surface heat flux on twin cyclone structure during their explosive development over the East Asian marginal seas on 23 January 2008, Weather and Climate Extremes, 23(January), 100198, doi:10.1016/j.wace.2019.100198.

Yu, L., Z. Zhang, S. Zhong, M. Zhou, Z. Gao, H. Wu, and B. Sun (2011), An intercomparison of six latent and sensible heat flux products over the southern ocean, Polar Research, 30(SUPPL.1), 1-27, doi:10.3402/polar.v30i0.10167.

Zeng, X., M. Zhao, and R. E. Dickinson (1998), Intercomparison of bulk aerodynamic algorithms for the computation of sea surface fluxes using TOGA COARE and TAO data, Journal of Climate, 11(10), 2628-2644, doi:10.1175/15200442(1998)011<2628:IOBAAF>2.0.CO;2. 
Table 1: List of instruments onboard $R / V$ Investigator comprising the NOAA PSD flux system

\begin{tabular}{|c|c|c|c|c|}
\hline Instrument & Parameters & Units & $\begin{array}{l}\text { Sensor } \\
\text { height (z) }\end{array}$ & $\begin{array}{l}\text { Sampling } \\
\text { rate }\end{array}$ \\
\hline $\begin{array}{l}\text { Ultrasonic 3-axis anemometer } \\
\text { (Metek uSonic-3) }\end{array}$ & $\begin{array}{l}\text { Wind speed } U_{z} \\
\text { Wind direction }\end{array}$ & $\mathrm{ms}^{-1}$ & $21 \mathrm{~m}$ & $10 \mathrm{~Hz}$ \\
\hline Systron-Donner motion-pak unit & $\begin{array}{l}\text { inertial navigation } \\
\text { system }\end{array}$ & & & $10 \mathrm{~Hz}$ \\
\hline $\begin{array}{l}\text { Precision Spectral Pyranometer } \\
\text { (Eppley PSP) }\end{array}$ & $\begin{array}{l}\text { solar downwelling } \\
\text { radiative flux }\end{array}$ & $\mathrm{Wm}^{-2}$ & $12 \mathrm{~m}$ & $1 \mathrm{~Hz}$ \\
\hline $\begin{array}{l}\text { Precision Infrared Radiometer } \\
\text { (Eppley PIR/pyrgeometer) }\end{array}$ & $\begin{array}{l}\text { IR downwelling } \\
\text { radiative flux }\end{array}$ & $\mathrm{Wm}^{-2}$ & $12 \mathrm{~m}$ & $1 \mathrm{~Hz}$ \\
\hline Vaisala/HMT335 & $\begin{array}{l}\text { Air temperature }\left(T_{a}\right) \\
\text { Humidity }\end{array}$ & $\begin{array}{l}{ }^{\circ} \mathrm{C} \\
\mathrm{g} / \mathrm{kg}\end{array}$ & $19.5 \mathrm{~m}$ & $1 \mathrm{~Hz}$ \\
\hline Vaisala/PTB220 & Pressure & mbar & & $10 \mathrm{~Hz}$ \\
\hline $\begin{array}{l}\text { Floating (YSI 46040) Thermistor, } \\
\text { deployed off port side with } \\
\text { outrigger (Sea Snake) }\end{array}$ & $\begin{array}{l}\text { Near-skin sea surface } \\
\text { temperature } \\
\left(T_{s}\right)\end{array}$ & ${ }^{\circ} \mathrm{C}$ & $-0.05 m$ & $10 \mathrm{~Hz}$ \\
\hline $\begin{array}{l}\text { Optical precipitation sensor } \\
\text { (ORG-815 DA) }\end{array}$ & Rain rate & $\mathrm{mmh}^{-1}$ & $20 \mathrm{~m}$ & $1 \mathrm{~Hz}$ \\
\hline $\begin{array}{l}\text { Li-COR } 7500 \text { Open Path } \\
\text { CO2/H20 Gas Analyzer }\end{array}$ & $\begin{array}{l}\text { Densities of carbon } \\
\text { dioxide and water } \\
\text { vapour }\end{array}$ & $\mathrm{Kgm}^{-3}$ & $21 \mathrm{~m}$ & $10 \mathrm{~Hz}$ \\
\hline Riegl laser altimeter & Wave height $\gamma$ & $\mathrm{m}$ & $20 \mathrm{~m}$ & $10 \mathrm{~Hz}$ \\
\hline
\end{tabular}


Table 2: Details of the 9 identified extratropical cyclones during $R / V$ Investigator voyage

\begin{tabular}{lll}
\hline & From & To \\
\hline 1. & 16 March 15 UTC & 17 March 14 UTC \\
\hline 2. & 29 March 05 UTC & 29 March 23 UTC \\
\hline 3. & 31 March 05 UTC & 01 April 08 UTC \\
\hline 4. & 04 April 01 UTC & 05 April 05 UTC \\
\hline 5. & 06 April 21 UTC & 07 April 23 UTC \\
\hline 6. & 08 April 12 UTC & 09 April 11 UTC \\
\hline
\end{tabular}

Table 3: Error statistics for hourly turbulent fluxes as measured by eddy covariance (EC) and inertial dissipation (ID) methods and hourly COARE 3.5 bulk fluxes for the voyage. Sample size for hourly data is given in bracket in the header.

\begin{tabular}{|c|c|c|c|c|c|c|c|c|c|c|c|c|}
\hline & \multicolumn{4}{|c|}{ Wind stress (445) } & \multicolumn{4}{|c|}{ Sensible heat flux (445) } & \multicolumn{4}{|c|}{ Latent heat flux (263) } \\
\hline & EC & ID & $E C+I D$ & COARE & EC & ID & $E C+I D$ & COARE & EC & ID & $E C+I D$ & COARE \\
\hline Mean & 0.22 & 0.22 & 0.22 & 0.20 & 24.59 & 20.60 & 22.59 & 15.23 & 90.01 & 111.65 & 100.83 & 87.42 \\
\hline Average & \multicolumn{2}{|c|}{0.217} & \multicolumn{2}{|r|}{0.208} & \multicolumn{2}{|c|}{22.59} & \multicolumn{2}{|c|}{18.91} & \multicolumn{2}{|c|}{100.83} & \multicolumn{2}{|c|}{94.13} \\
\hline RMSE & \multicolumn{2}{|c|}{0.05} & \multicolumn{2}{|r|}{0.05} & \multicolumn{2}{|c|}{15.77} & \multicolumn{2}{|c|}{13.82} & \multicolumn{2}{|c|}{38.76} & \multicolumn{2}{|c|}{24.55} \\
\hline $\begin{array}{l}\text { Uncertainty= } \\
\text { RMSE*100/Av } \\
\text { erage }\end{array}$ & \multicolumn{2}{|c|}{22.58} & \multicolumn{2}{|r|}{21.99} & \multicolumn{2}{|c|}{71.59} & \multicolumn{2}{|c|}{70.01} & \multicolumn{2}{|c|}{38.44} & \multicolumn{2}{|c|}{26.08} \\
\hline $\begin{array}{l}\text { Absolute } \\
\text { Percent bias }\end{array}$ & \multicolumn{2}{|c|}{1.28} & \multicolumn{2}{|r|}{7.44} & \multicolumn{2}{|c|}{16.25} & \multicolumn{2}{|c|}{32.59} & \multicolumn{2}{|c|}{24.04} & \multicolumn{2}{|c|}{13.29} \\
\hline
\end{tabular}


Table 4: Mean bulk fluxes and flux-related state variables corresponding to six categories as discussed in section 3.3. Refer to appendix for full variable names and units.

\begin{tabular}{lllllll}
\hline & Voyage & w/o eddies & Cold eddy & Warm eddy & No rain & rain \\
\hline $\boldsymbol{U}_{\mathbf{1 0 n}}$ & 10.2396 & 9.3348 & 10.6126 & 13.3147 & 9.4825 & 11.7376 \\
$\boldsymbol{\tau}$ & 0.2104 & 0.1665 & 0.1986 & 0.3982 & 0.1650 & 0.3001 \\
$\boldsymbol{T}_{\boldsymbol{a}}$ & 9.4807 & 10.2721 & 8.9224 & 7.0986 & 9.6274 & 9.1902 \\
$\boldsymbol{T}_{\boldsymbol{s}}$ & 10.4988 & 11.5789 & 8.2041 & 9.2209 & 10.8987 & 9.7076 \\
\hline $\boldsymbol{\Delta}$ & 1.0174 & -1.3068 & 0.7182 & -2.1248 & -1.2700 & -0.5174 \\
\hline $\boldsymbol{H}_{\boldsymbol{S}}$ & 12.1593 & 15.3084 & -14.9620 & 34.8673 & 13.7658 & 8.9803 \\
$\boldsymbol{q}_{\boldsymbol{a}}$ & 6.0557 & 6.2840 & 6.3024 & 4.8431 & 5.7639 & 6.6337 \\
$\boldsymbol{q}_{\boldsymbol{s}}$ & 7.8449 & 8.3624 & 6.7208 & 7.2645 & 8.0326 & 7.4736 \\
$\boldsymbol{\Delta} \boldsymbol{q}$ & 1.7886 & 2.0785 & 0.4183 & 2.4216 & 2.2680 & 0.8399 \\
$\boldsymbol{H}_{\boldsymbol{I}}$ & 59.4618 & 65.1879 & 5.8216 & 106.3480 & 70.4262 & 37.7650 \\
\hline
\end{tabular}



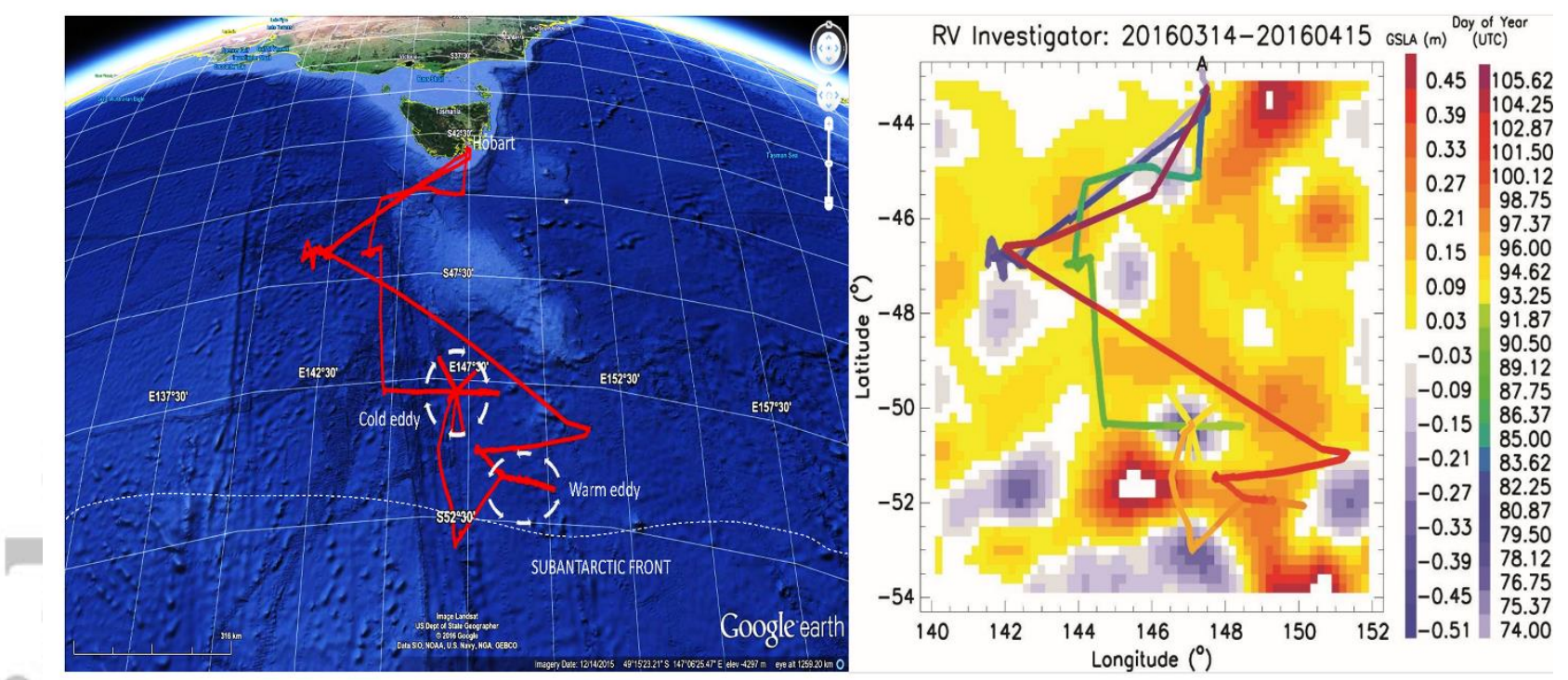

Figure 1: (left) The voyage path of the cruise from 14 March 2016 to 15 April 2016. The ship left Hobart and travelled as far south as $53^{\circ}$ latitude (right) Map showing the timeline of the voyage in the solar day and gridded sea level anomalies (GSLA) in meters during R/V Investigator voyage. 

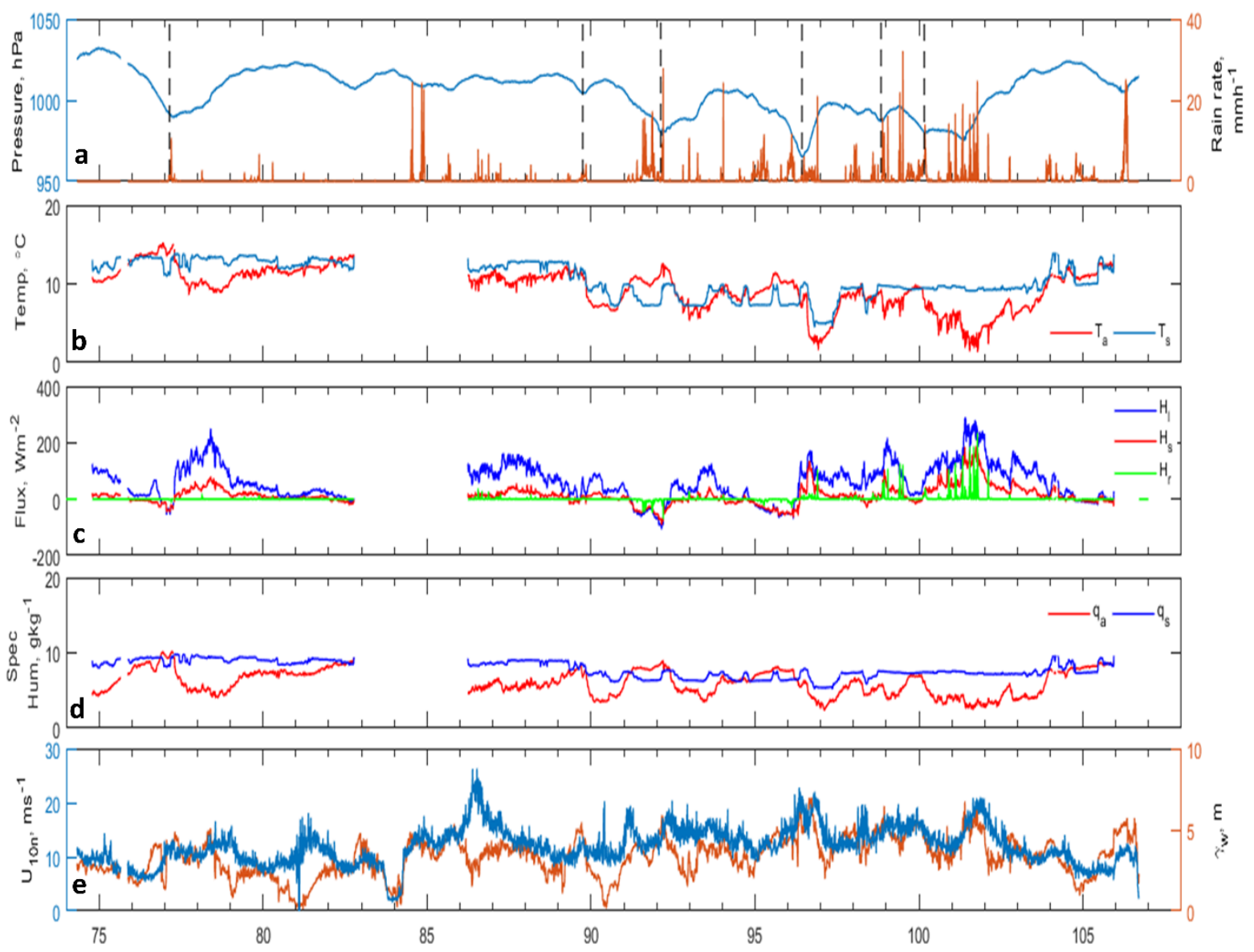

Figure 2: Time series of (a) surface pressure, $P$ in mbar with passages of cold fronts shown as dashed lines and rain rate in $\mathrm{mmh}^{-1}$ (b) surface air temperature, $T_{a}$ and sea surface temperature, $T_{s}$ in ${ }^{\circ} \mathrm{C}$ (c) Sensible heat flux, $H_{s}$, latent heat flux, $H_{l}$ and rain heat flux, $H_{r}$ in $\mathrm{Wm}^{-2}$ (d) Specific humidity, $q_{a}$, and sea surface saturation specific humidity, $q_{s}$ in $\mathrm{gkg}^{-1}$ (e) $10-\mathrm{m}$ neutral wind speed, $U_{10 n}$ in $\mathrm{ms}^{-1}$ and full sea significant wave height, $\gamma$ in meters during R/V Investigator voyage. The $\mathrm{x}$-axis represents the solar day. No flux observations were available from 23 to 26 March due to ship maintenance. 

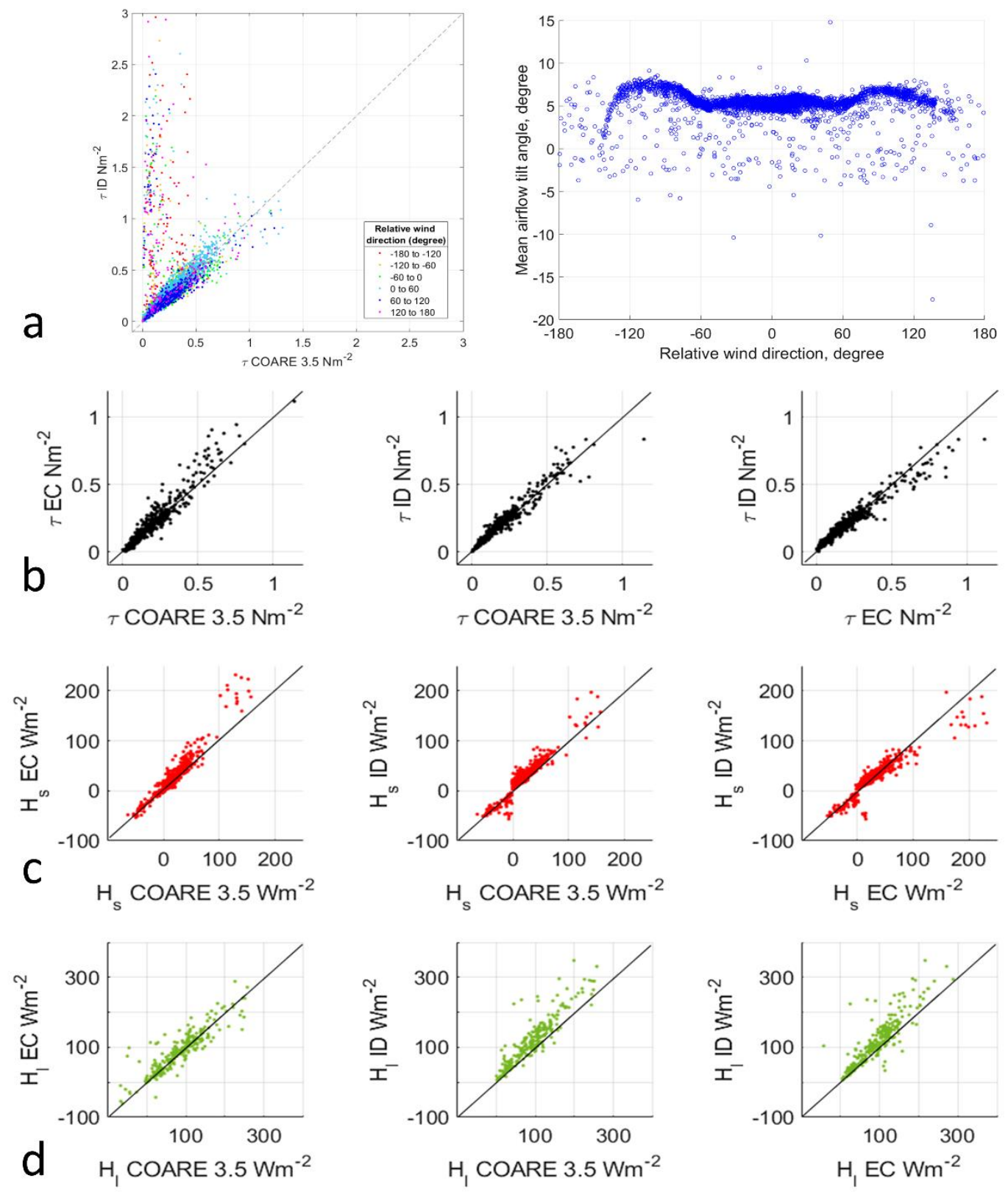

Figure 3: (a) (left) Scatterplot between wind stress, $\tau$, obtained by inertial dissipation method (ID) and COARE 3.5 bulk model grouped by relative wind direction (in degree). (right) scatterplot between relative wind direction (in degree) and mean airflow tilt angle (in degree). Scatterplots for hourly flux values obtained from eddy covariance method (EC), inertial dissipation method (ID), together as the direct method and COARE 3.5 bulk parameterization model for (a) wind stress $\tau$, (b) Sensible heat flux $H_{s}$, and (c) Latent heat flux $H_{l}$ during $R / V$ Investigator voyage. The line represents 1:1 line in all scatter plots. 


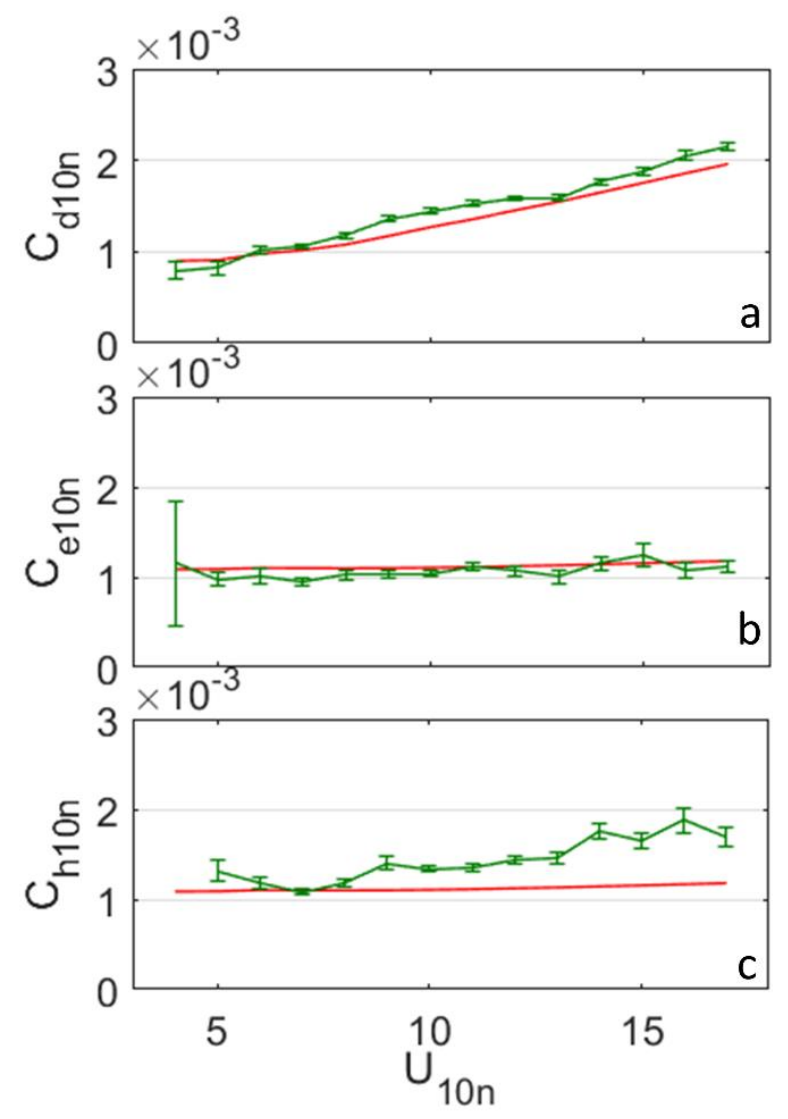

Figure 4: The measured (green) and modelled (red) 10-m neutral transfer coefficient for (a) momentum, $C_{d 10 n}$ (b) sensible, $C_{h 10 n}$ (c) latent heat flux $C_{e 10 n}$ as a function of 10m neutral wind speed $U_{10}$. Error bars indicate statistical uncertainty of one standard deviation divided by the square root of number of observations in the wind speed bin. 


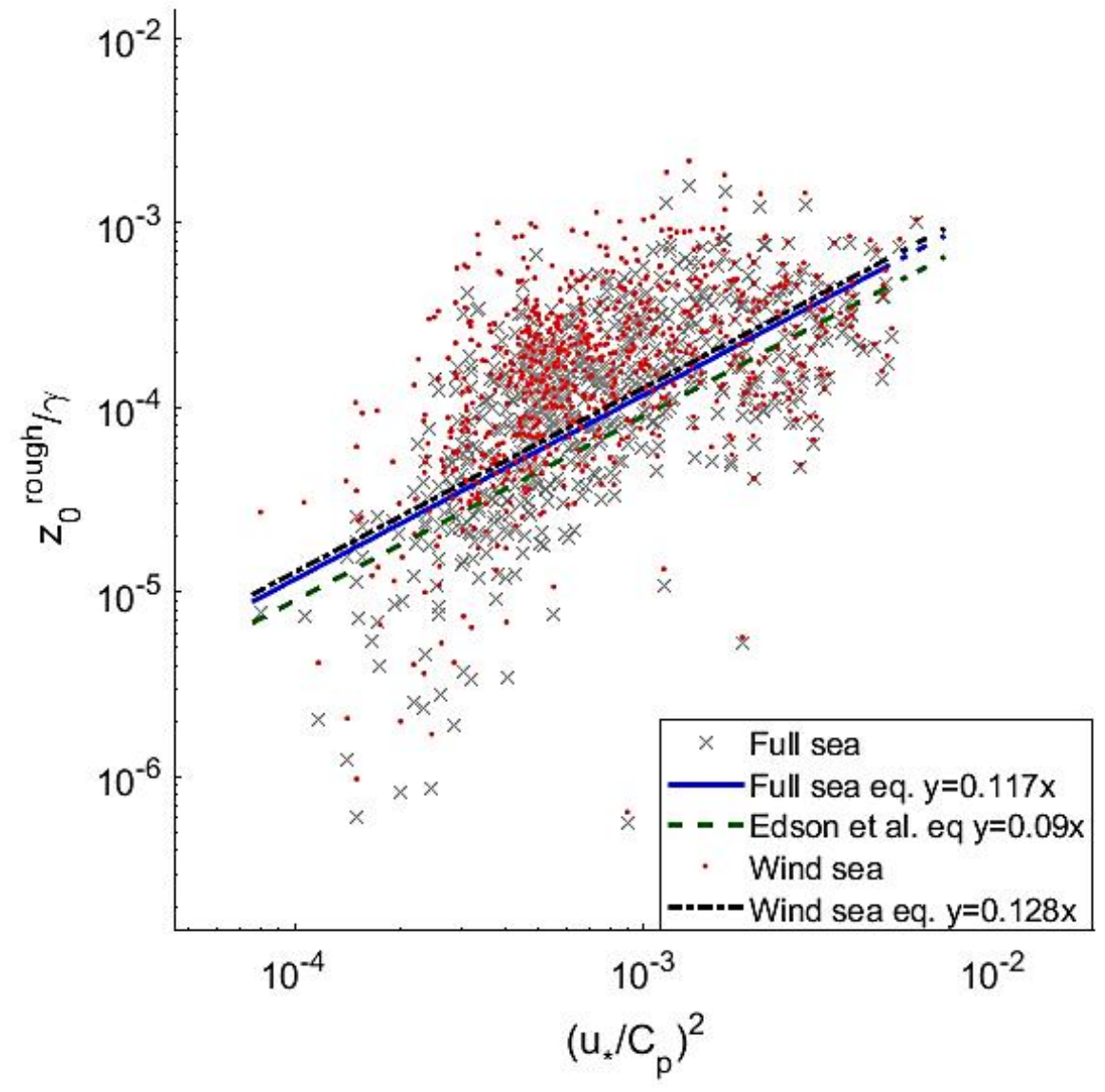

Figure 5: The surface roughness, $z_{0}^{\text {rough }}$ scaled by significant wave height, $\gamma$ as a function of bin averaged inverse wave age squared on log-log scale. Edson et al. represents the relation when $D=0.09$. 
a
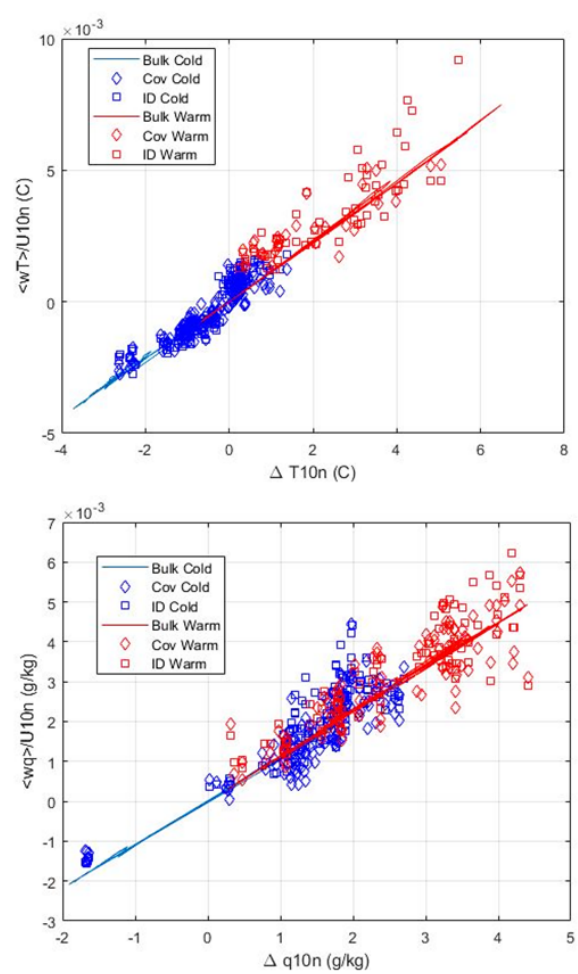
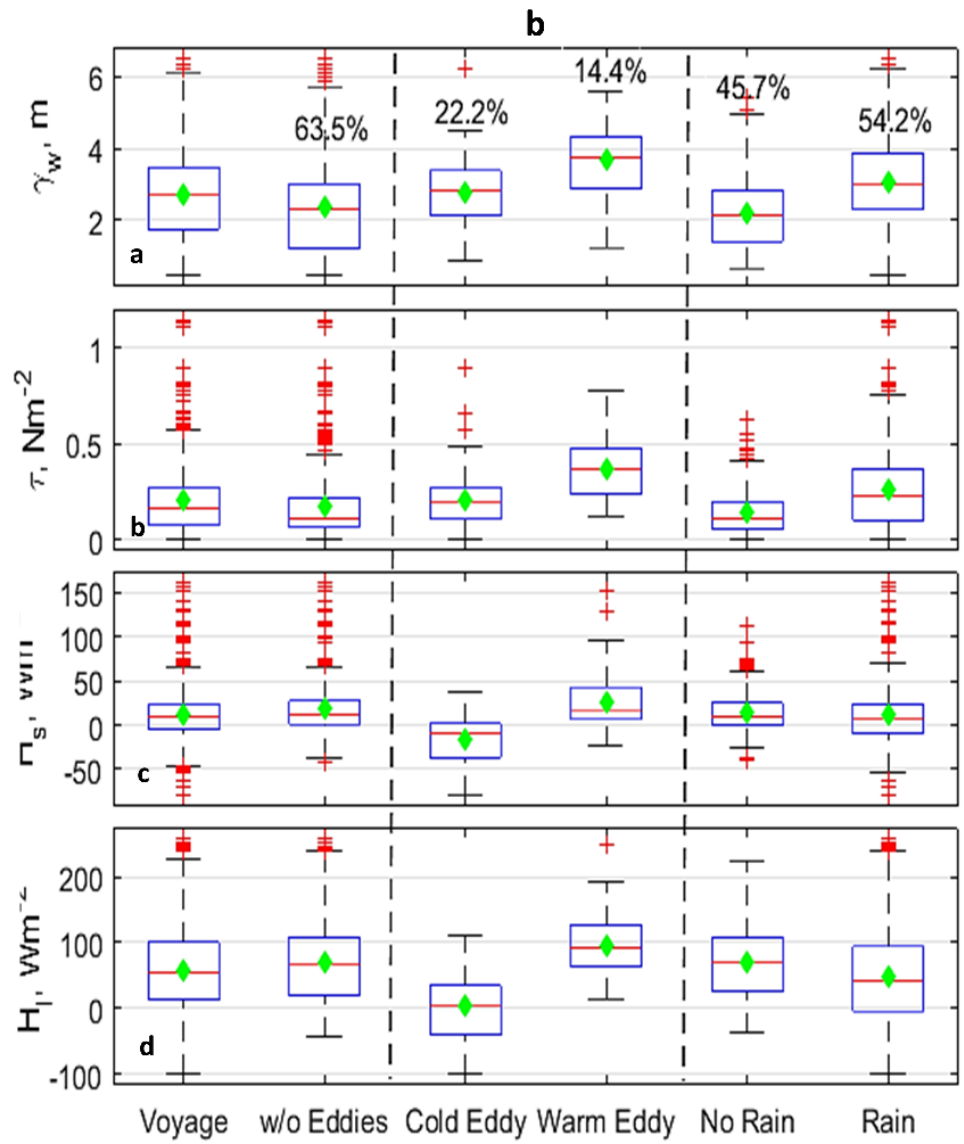

Figure 6(a). Turbulent flux divided by the neutral $10-\mathrm{m}$ wind speed as a function of the 10-m neutral sea-air difference (upper panel - temperature; lower panel - humidity). The red denotes the warm eddy while the blue denotes the cold eddy. The straight line is the COARE 3.5 bulk value; diamonds the covariance (EC) flux; squares the ID flux.

6(b): (a) Wind-sea significant wave height, $\gamma_{w}$ (b) Wind stress, $\tau$ (c) Sensible heat flux, $H_{s}$ (d) Latent heat flux, $H_{l}$ distributions using COARE 3.5 bulk fluxes during the voyage, over the eddies and during rainy conditions. A diamond indicates mean and red line indicates median of the distribution. The sample size for each distribution is given in $\%$ in (a) and is same for the rest. Missing data are excluded. 


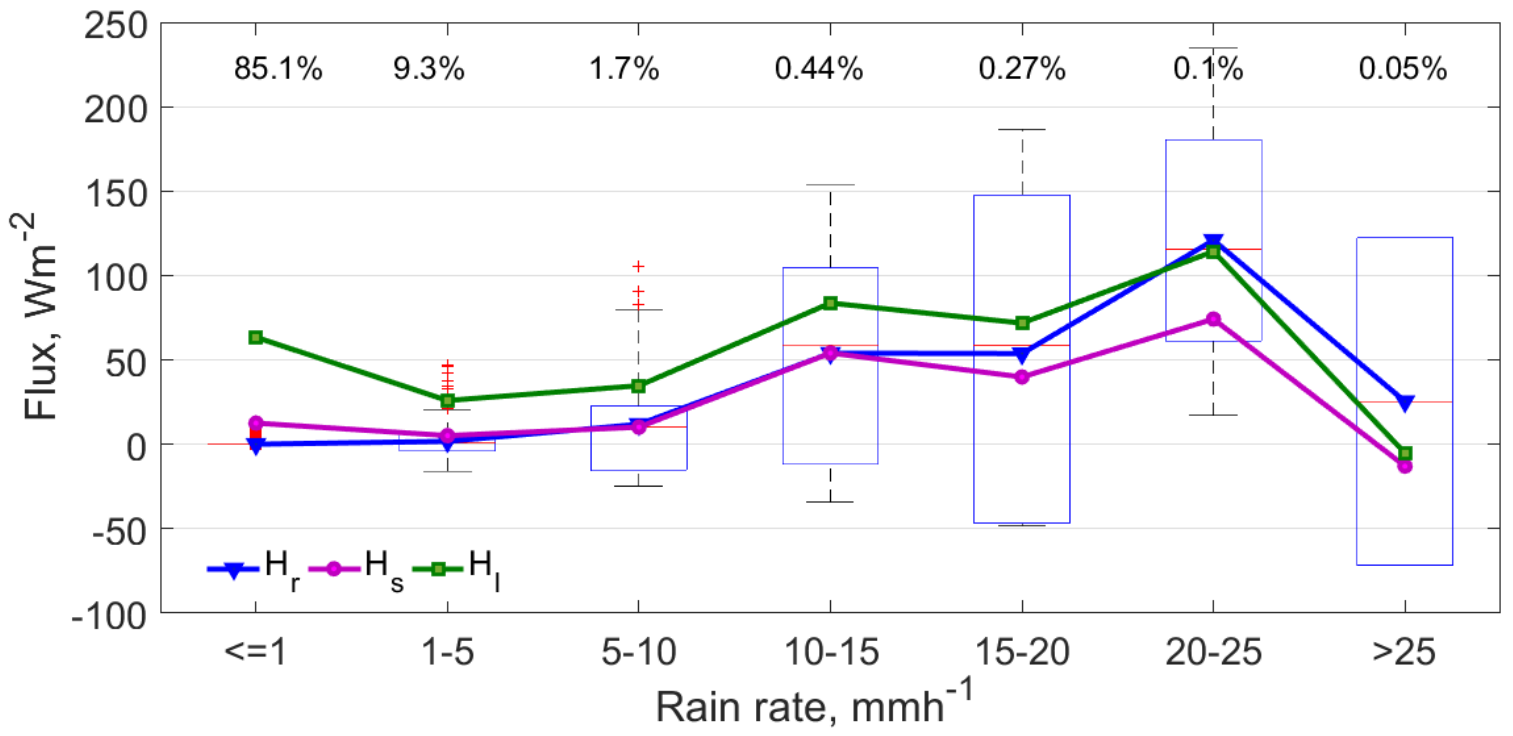

Figure 7: Distribution rain heat flux $\left(H_{r}\right)$ along with mean values for each bin during the voyage classified on rain rate, $R\left(\mathrm{mmh}^{-1}\right)$ using 10 -minute flux values. Mean values of $H_{s}$ and $H_{l}$ are also plotted for each bin. The \% of data is mentioned for each distribution out of all rain events i.e. when $R>0 \mathrm{mmh}^{-1}$. 

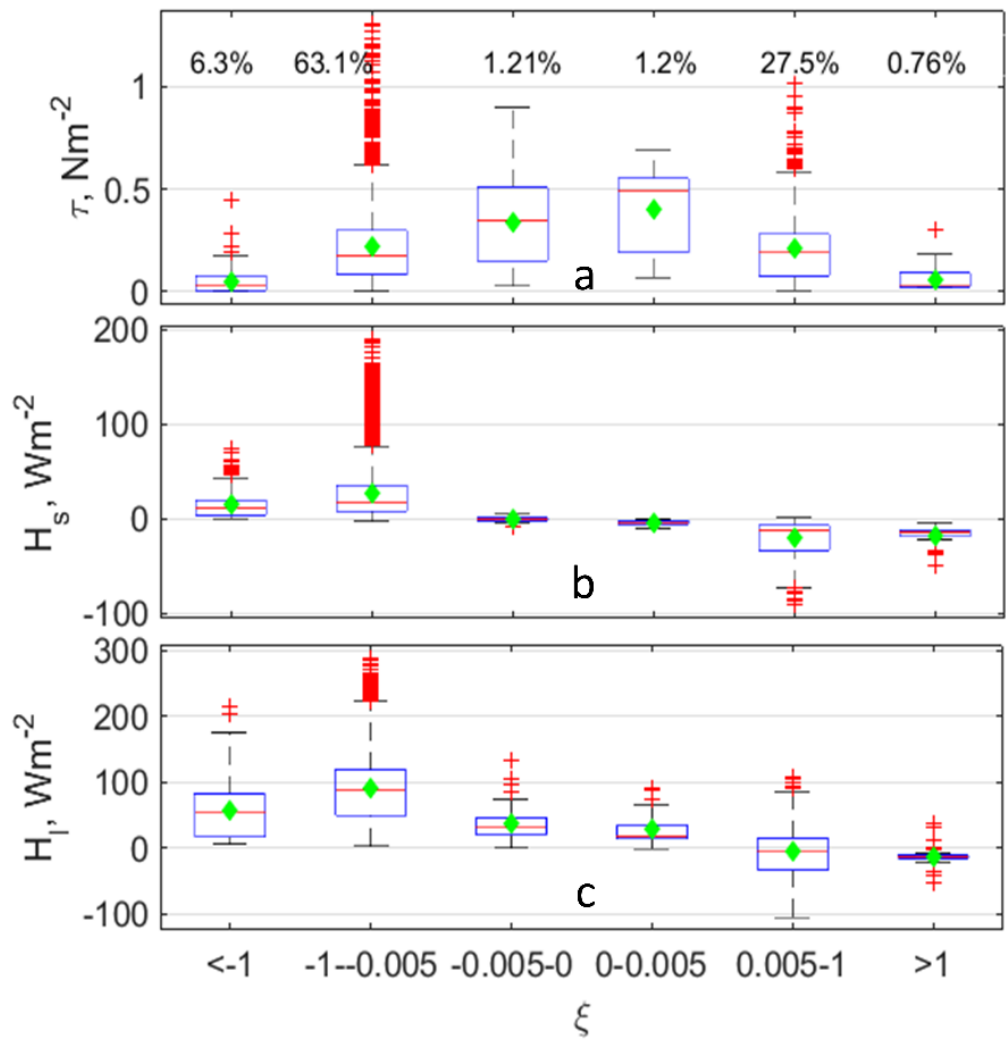

Figure 8: Distributions of (a) wind stress, $\tau$ (b) Sensible heat flux, $H_{s}$ and (c) Latent heat flux, $H_{l}$ categorized on the Monin-Obukhov stability parameter $(\xi=z / L)$. The $\%$ of data for each distribution is given for $\tau$ (same for $H_{s}$ and $H_{l}$ ). Missing data are excluded. 

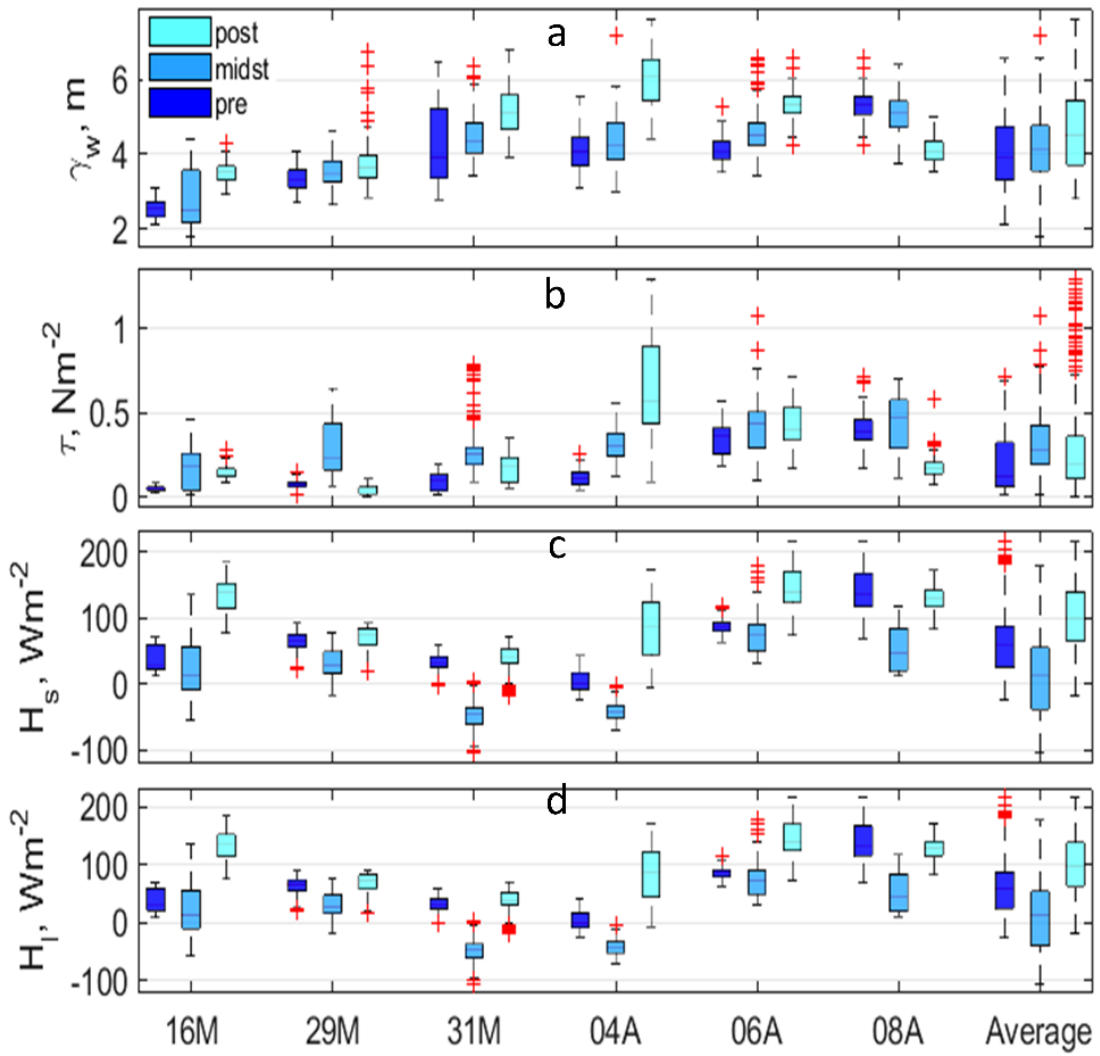

Figure 9: (a) Wind-sea significant wave height, $\gamma_{w}$ (b) Wind stress, $\tau$ (c) Sensible heat flux, $H_{s}$ (d) Latent heat flux, $H_{l}$ distributions using COARE 3.5 data shown here as boxplots as noted during pre-, midst- and post- conditions of 6 extratropical cyclones. The $x$-axis represents the dates where Suffix-M is for March and Suffix-A is for April month respectively. The average distributions of fluxes are calculated by combining all pre-, midst- and post- distributions separately. 